\title{
Integration of 103 semi-volatile organic compounds into one multi-analyte method for human serum analysis: An innovative approach within exposure assessment
}

Xiu Wang, Kai Huang, Lingshuai Zeng, Xiu Zhang, Danqi Cheng, Ruifang Li, Yikai Zhou and Tao Jing*

State Key Laboratory of Environment Health (Incubation), Key Laboratory of Environment and Health, Ministry of Education, Key Laboratory of Environment and Health (Wuhan), Ministry of Environmental Protection School of Public Health, Tongji Medical College, Huazhong University of Science and Technology, \#13 Hangkong Road, Wuhan, Hubei 430030, China

*Corresponding Author:

Tao Jing, E-mail: jingtao@hust.edu.cn

Address: School of Public Health, Tongji Medical College, Huazhong University of Science and Technology, \#13 Hangkong Road, Wuhan, Hubei, 430030, China

Tel: +86(27)-83552611

Fax: +86(27)-83657765 
Table of Contents

Text S1 Chemicals and reagents

Text S2 Validation experiments

Text S3 Statistical analysis

Text S4 Performance of C18 and HLB columns

Text S5 Optimization of GC-EI-MS/MS analysis

Text S6 Calibration curves

Text S7 Comparison of serum concentrations of SVOCs

Text S8 Correlations among serum SVOCs

Table S1. Physicochemical properties data of the studied SVOCs gathering from the PubChem database.

Table S2. The full name and abbreviation pairs of priority pollutants including 16 PAHs, 5 PBDEs, 7 PAEs and 7 PCBs.

Table S3. Studied SVOCs, CAS number, retention time, and MRM transitions ( $\mathrm{m} / \mathrm{z})$.

Table S4. Optimal instrumental configuration and conditions.

Table S5. Analytical performance of the multi classes of SVOCs.

Table S6. Comparison of the developed method with others reported.

Table S7. Concentrations of SVOCs in serum samples $\left(\mu \mathrm{g} \mathrm{L}^{-1}, \mathrm{n}=99\right)$.

Table S8. Comparison of mean concentrations of 7 SVOCs in this study with other studies $\left(\mu g \mathrm{~L}^{-1}\right)$.

Figure S1. Pearson correlation of logKow value and recovery rate (\%) of target compounds. $\mathrm{x}=\log$ Kow value, $\mathrm{y}=$ recovery $(\%), \mathrm{r}=0.68, \mathrm{p}$-value $=4.37 \mathrm{e}-15$.

Figure S2. Recoveries (A) and matrix effects (B) of target analytes in serum samples and comparison with different SPE cartridges. Compounds are arranged from left to right according to LogKow value from small to large.

Figure S3. The influence of elution solvent mixtures on recovery efficiency $(n=3)$. The volume ratio of $2 \mathrm{~mL}$ of Hex/DCM (v/v, 8:2), $2 \mathrm{~mL}$ of Hex/EtAc (v/v, 8:2) and $2 \mathrm{~mL}$ of $\operatorname{Hex} / \mathrm{DCM}(\mathrm{v} / \mathrm{v}, 1: 1)$ were tested.

Figure S4. Reconstructed TIC chromatogram of 103 SVOCs (fetal bovine serum) 
spiked with the target compounds $\left(40 \mu \mathrm{g} \mathrm{L}^{-1}\right)$.

Figure S5. The analysis of QA/QC samples spiked with the target compounds in real sample testing $\left(10 \mu \mathrm{g} \mathrm{L}^{-1}\right)$.

Figure S6. Comparison of Logarithmic conversion concentrations of 7 selected SVOCs in this study with other studies $\left(\mu \mathrm{g} \mathrm{L}^{-1}\right)$.

Figure S7. Heat map of pairwise correlations between chemical concentrations in serum. Red means positive correlation, white indicates no correlation, and blue represents negative correlation.

\section{Reference}




\section{Text S1 Chemicals and reagents}

All solvents used in this study were of chromatographic grade, pesticide residues free and purchased from Merck (Darmstadt, Germany). Water was obtained from a Milli-Q water purification system (Millipore, Bedford, MA, USA). Commercial helium (99.99\%) was used as the GC carrier gas. Pure nitrogen was supplied by ANPEL LGN large flow nitrogen generator (Shanggai, China). The Supelclean ${ }^{\mathrm{TM}}$ ENVI $^{\mathrm{TM}}$ Florisi $^{\circledR}$ $3 \mathrm{~mL} 500 \mathrm{mg}$ cartridges (Supelco, Poole, USA) were purchased from Sigma-Aldrich (St Louis, MO, USA). The Oasis ${ }^{\circledR}$ HLB cartridges $\left(3 \mathrm{~cm}^{3} / 60 \mathrm{mg}\right)$ were purchased from Waters Corporation (Milford, MA, USA). The Cleanert C18 cartridges $\left(3 \mathrm{~cm}^{3} / 500 \mathrm{mg}\right)$ were purchased from Agela Technologies Corporation (Shanghai, China). All glassware was heated at $450{ }^{\circ} \mathrm{C}$ for more than $6 \mathrm{~h}$.

The target analytes including CAS numbers, molecular weights, and physical properties were summarized in Table S1. The standard mix solution of containing 68 pesticides was obtained from Alta-Scientific Co., Ltd. Tianjin, China. PAEs, PCBs, PBDEs and PAHs were purchased from Dr. Ehrenstorfer (Augsburg, Germany). The full name and abbreviation pairs of pollutants mentioned above were exhibited in Table S2. Internal standards (ISs) solutions of bis(2-ethylhexyl) phthalate-d4, diethyl phthalate-d4, naphthalene-d8, phenanthrene-d10, perylene-d12, chlorpyrifos-(diethyld10) (diethyl d10) and Heptachlor Epoxide (Isomer B) were obtained from AccuStandard CO. USA. ${ }^{13} \mathrm{C}_{12}$-isotope-labeled $\quad \mathrm{PCB} \quad\left({ }^{13} \mathrm{C}_{12}\right.$-PCB28/52/101/118/138/153/180, 99\%) standard solutions were purchased from Wellington Laboratories Inc. (Guelph, Ontario, Canada). Dichlorvos-d6, Malathion-d10, Diazinond10, Fenthion-d6 and coumaphos-d10 standard solutions were purchased from AltaScientific Co., Ltd. Tianjin, China. ${ }^{13} \mathrm{C}_{12^{-}} p, p^{\prime}$-DDT and ${ }^{13} \mathrm{C}_{12}$-PBDE-77 standard solutions were purchased from Cambridge Isotope Laboratories, Inc., Andover, Massachusetts. Propyzamide-d3 (phenyl-2,4,6-d3) and $\gamma$-BHC-d6 standard solutions were purchased from CDN Isotopes, Quebec, Canada. Atrazine-d5 standard solutions was purchased from TCR Inc., North York, Canada. ${ }^{13} \mathrm{C}_{6}$-Hexachlorobenzene, acetochlor-d11 and ethion-d20 standard solutions were purchased form Dr. Ehrenstorfer GmbH, Germany. Fenpropathrin-d5 standard solutions was purchased 
from Cato Research Chemicals Inc., Guangzhou, China. Fetal bovine serum was acquired from Thermo Fisher Scientific, USA. The stock solutions of standard mixtures were prepared in hexane (Hex) and stored in glass vials at $-20^{\circ} \mathrm{C}$.

\section{Text S2 Validation experiments}

The validation experiments were studied using fetal bovine serum instead of the blank human serum. The quality control (QC) samples were generated by spiking 103 SVOCs $\left(10 \mu \mathrm{g} \mathrm{L}^{-1}\right)$ and 28 kinds of ISs (0.5 ng of each IS) following the sample pretreatment procedure. The absolute and relative recoveries were obtained from the spiking experiments performed at three concentration levels $(0.2,2,20 \mathrm{ng})$ of 103 SVOCs. The absolute recovery, calculated relative to ISs, with ISs added to the final extracts and with a calibration curve prepared in pure hexane. The relative recovery, calculated relative to ISs, with ISs added to the fetal bovine serum and with a calibration curve prepared in final extracts. The QC samples were analyzed in parallel with real serum samples. Furthermore, procedural blank samples (deionized water and fetal bovine serum were used, respectively) were analyzed together with each batch of samples to control background contamination. All of glass tubes were cleaned and heattreated at $480{ }^{\circ} \mathrm{C}$ for $5 \mathrm{~h}$, and the related plastic materials were avoided. The Teflonlined screw caps and Teflon-lined silicone septa should be ultrasonicated in methanol to minimize blank contamination. The isotopically labelled surrogates were added in each real sample to control the extraction efficiency and correct possible matrix effects.

\section{Text S3 Statistical analysis}

The comparison of SVOCs levels in human serum samples were studied using the Student's t-test. We replaced the undetectable values with the limit of detection divided by the square root of two. The Spearman's method was used to explore the guiding significance of LogKow in the process of pollutant extraction and calculate the correlation coefficients of SVOCs. The statistical analysis was conducted using R 4.0.2 with a significance level of 0.05 for two-tailed testing. 


\section{Text S4 Performance of C18 and HLB columns}

C18 and HLB cartridges columns were tested for their extraction efficiency in purifying real blood samples. Firstly, $0.5 \mathrm{~mL}$ serum sample was diluted with $0.5 \mathrm{~mL}$ Milli-Q water. Then, $1 \mathrm{~mL}$ ACN was added to precipitate proteins under ultrasonication in a water bath for $10 \mathrm{~min}$.

Before loading the serum mixed aqueous solution, the $\mathrm{C} 18$ cartridges were washed using $5 \mathrm{~mL}$ methanol and were conditioned with $3 \mathrm{~mL}$ ACN and $5 \mathrm{~mL}$ Milli-Q water. The serum mixed aqueous solution was loaded using gravity flow. The C18 column was then rinsed and washed with $5 \mathrm{ml}$ Milli-Q water then evacuated for about 1 hour to remove residual water. Finally, the target components were eluted with $3 \mathrm{~mL}$ methanol and $3 \mathrm{~mL}$ ACN: methanol $(90: 10, \mathrm{v} / \mathrm{v})$. The pooled eluate was evaporated to near dryness under a gentle nitrogen stream, and reconstituted in $0.1 \mathrm{~mL}$ Hex for GCMS/MS analysis.

Before loading, the serum sample was treated as mentioned above. The HLB cartridges were washed and preconditioned with $3 \mathrm{~mL}$ DCM, $5 \mathrm{~mL}$ methanol and $5 \mathrm{~mL}$ Milli-Q water. The serum mixed aqueous solution got past through HLB cartridges by gravity flow. The HLB column was then rinsed and washed with $5 \mathrm{ml}$ Milli-Q water: methanol (95: 5, v/v) and then evacuated for about 1 hour to remove residual water. Finally, the target components were eluted with $3 \mathrm{~mL}$ methanol and $3 \mathrm{~mL}$ DCM: Hex (10:90, v/v). The pooled eluate was evaporated to near dryness under a gentle nitrogen stream, and reconstituted in $0.1 \mathrm{~mL}$ Hex for GC-MS/MS analysis.

\section{Text S5 Optimization of GC-EI-MS/MS analysis}

The instrumental conditions for GC-EI-MS/MS for multi-residue analysis were established. For multi-class SVOCs including PAHs, PAEs, PCBs, PBDEs and pesticides, a DB-5MS column was selected to allow sufficient separation. We further optimized the temperatures of injection, transfer line and ion source to enhance sensitivity and reduce the residual noise of heavy molecules such as $\mathrm{BaP}$, IcdP and BghiP. Therefore $300{ }^{\circ} \mathrm{C}$ injector temperature, $280{ }^{\circ} \mathrm{C}$ transfer line temperature and 280 ${ }^{\circ} \mathrm{C}$ ion source temperature were established via optimization. Then, the peak position 
and ion fragments were optimized by the full scan mode, and the specific precusor ions were studied. In the MRM mode, the collision energy sequence with an interval of 2-5 $\mathrm{eV}$ between 5-60 eV of precursor ions was set to find the optimal collision energy when the characteristic product ion response was the highest to achieve high selectivity and sensitivity. The above parameters were acquired from analysis of diluted standard mixtures $\left(10 \mu \mathrm{g} \mathrm{mL}^{-1}\right)$. The retention times and MRM conditions for the target compounds are presented in Table S3.

Reconstructed total ion chromatogram (TIC) of the real sample (fetal bovine serum) spiked with 103 SVOCs (40 $\mu \mathrm{g} \mathrm{L}^{-1}$ each) was shown in Figure S4. The multiple peaks based on the isomers appeared on the chromatogram of most of the SPs (permethrin, cypermethrin, cyfluthrin, deltamethrin), which would be quantified together. In TIC, the peaks of some SVOCs overlapped with each other, namely, their separation was insufficient. However, the quantitative and qualitative ions of these SVOCs shown in Table S3 seemed utterly different that did not interfere with the determination. Therefore, the present chromatographic method by MRM appeared to be satisfactory for the determination of all SVOCs without their affecting each other.

\section{Text S6 Calibration curves and reproducibility}

Calibration curves using fetal bovine serum samples with 8 concentrations of each analyte were obtained as $0.5,1,2,5,10,50,100$ and $200 \mu \mathrm{g} \mathrm{L}^{-1}$, and the internal standard concentration of $1 \mu \mathrm{g} \mathrm{L}{ }^{-1}$, to determine the linear working range. Taking the concentration of analytes added as the abscissa coordinate, taking the ration of the target compound to internal standard chromatographic peak area as the ordinate to construct the calibration curves, in triplicate. The correlation coefficient of this method was at least 0.998 or more, and acceptable linearity was obtained.

Interday- and intraday- precisions were studied by using the RSD values of 7 measurements of each real sample taken on one day and five continuous days, respectively. According to the relative recovery rate, the arithmetic mean of the chromatographic peak area $(n=3)$ is considered to evaluate the accuracy of the method. 


\section{Text S7 Comparison of serum concentrations of SVOCs}

The concentrations of DnBP, DEHP, PCB-153, $p, p^{\prime}$-DDE, $\beta-\mathrm{HCH}$, hexachlorobenzene and total PAH tested in this study were compared with those reported in the literature (Figure S6 and Table S8). The serum concentrations of DnBP and DEHP in general population were reported to increased gradually, which might be related to the popularity of plastic products and the lack of restrictive standards. Concentration of PCB-153 was in the median level of the reported values. However, $p, p$ '-DDE, $\beta-\mathrm{HCH}$ and hexachlorobenzene were observed at highest level in Chinese among all countries reported, which was consistent with Li's research. ${ }^{1}$ The same conclusion could also be found in PAH testing results. Except for the concentration of the total PAHs found in Poland pregnant woman $\left(298.25 \mu \mathrm{g} \mathrm{L}^{-1}\right)$, the concentration of total PAHs tested in this study was much higher than the samples from America and India.

\section{Text S8 Correlations among serum SVOCs}

Of all chemical concentrations, $773(28.6 \%)$ pairwise correlated with $r>0.40$; these pairs tended to be of the same chemical category $(60.4 \%)$. For example, correlations among PAHs from -0.73 to 0.90 , of which $\mathrm{BbF}$ and $\mathrm{BkF}$ showed the strongest correlation $(\mathrm{r}=0.98)$. Correlations among pesticides ranged from -0.81 to 0.95 , with the strongest correlation between ametryn and prometryn $(r=0.95)$ (Figure S7). But beyond that, there were some significant positive correlations between chemical concentrations of different classes. Pyr and o.p'-DDD $(r=0.92), \mathrm{BaA}$ and PCB-153 $(r=0.94)$, Chrysene and permethrin $(r=0.92)$, and BaP and permethrin $(r=$ 0.91) were strongly correlated with each other. In addition, there were some strong negative correlations not negligible among chemicals from different classes, with the strongest between Phe and parathionmethyl $(r=-0.84)$ and Phe and cypermethrin $(r=$ $-0.82)$. 
Table S1. Physicochemical properties data of the studied SVOCs gathering from the PubChem database and reported literatures.

\begin{tabular}{|c|c|c|c|c|c|c|c|c|}
\hline Compounds & CAS number & MW & $\log$ Kow & $\begin{array}{l}\text { Vapour pressure } \\
\left(\mathrm{atm}, 25^{\circ} \mathrm{C}\right)\end{array}$ & $\begin{array}{l}\text { Boiling point } \\
\left({ }^{\circ} \mathrm{C}\right)\end{array}$ & $\begin{array}{l}\text { Melting } \\
\text { point }\left({ }^{\circ} \mathrm{C}\right)\end{array}$ & $\begin{array}{l}\text { Water- } \\
\text { solubility } \\
\mathrm{mg} / \mathrm{L}\left(25^{\circ} \mathrm{C}\right)\end{array}$ & $\begin{array}{l}\text { Relative density } \\
\left(\text { water }=1 \mathrm{~g} / \mathrm{cm}^{3} \text {, }\right. \\
20^{\circ} \mathrm{C} \text { ) }\end{array}$ \\
\hline Naphthalene-d8 & $1146-65-2$ & 136.22 & 3.3 & $2.08705 \mathrm{E}-04$ & 218 & $80-82$ & - & 1.242 \\
\hline Naphthalene & $91-20-3$ & 128.17 & 3.3 & $1.11572 \mathrm{E}-04$ & 218 & $80-82$ & 30 & 0.99 \\
\hline Dichlorvos-d6 & 203645-53-8 & 227.01 & - & $1.89803 \mathrm{E}-03$ & 140 & - & - & 1.474 \\
\hline Dichlorvos & $62-73-7$ & 220.98 & 1.43 & $2.07392 \mathrm{E}-05$ & 140 & -60 & 10000 & 1.415 \\
\hline Mevinphos & 7786-34-7 & 224.15 & 1.2 & $1.68014 \mathrm{E}-07$ & $99-103$ & 21 & totally miscible & 1.25 \\
\hline DMP & $131-11-3$ & 194.18 & 1.6 & 4.04283E-06 & 282 & 2 & $<1000^{\mathrm{a}}$ & 1.19 \\
\hline Propham & $122-42-9$ & 179.22 & 2.6 & $1.83765 \mathrm{E}-07$ & 311.75 & 90 & 100 & 1.09 \\
\hline Acenaphthylene & $208-96-8$ & 152.19 & 3.93 & $6.30052 \mathrm{E}-06$ & 280 & $78-82$ & 3.93 & 0.899 \\
\hline Acenaphthene & $83-32-9$ & 154.21 & 3.92 & $2.88774 \mathrm{E}-06$ & 279 & $90-94$ & 3.47 & 1.06 \\
\hline DEP-d4 & $93952-12-6$ & 226.26 & 2.5 & - & 298-299 & -3 & - & 1.158 \\
\hline DEP & $84-66-2$ & 222.24 & 2.47 & $2.75648 \mathrm{E}-06$ & 298-299 & -3 & $1000^{\mathrm{a}}$ & 1.12 \\
\hline Fluorene & $86-73-7$ & 166.22 & 4.18 & 7.87565E-07 & 298 & $111-114$ & insoluble & 1.2 \\
\hline Ethoprophos & $13194-48-4$ & 242.34 & 3.59 & 4.98791E-06 & $86-91$ & -13 & $700^{\mathrm{a}}$ & 1.094 \\
\hline Trifluralin & $1582-09-8$ & 335.28 & 5.34 & $1.58826 \mathrm{E}-08$ & 139 & 48.5 & $<100^{\mathrm{b}}$ & 1.294 \\
\hline Phorate & $298-02-2$ & 260.38 & 3.56 & 8.37444E-07 & $118-120$ & -15 & insoluble & 1.167 \\
\hline$\alpha-\mathrm{BHC}$ & $319-84-6$ & 290.83 & 3.72 & $5.90674 \mathrm{E}-08$ & 373.64 & $156-161$ & 2 & 1.9 \\
\hline${ }^{13} \mathrm{C}_{6}$-Hexachlorobenzene & $93952-14-8$ & 290.74 & 5.6 & - & $323-326$ & $227-229$ & - & - \\
\hline Hexachlorobenzene & $118-74-1$ & 284.78 & 5.73 & $2.25769 \mathrm{E}-08$ & $323-326$ & $227-229$ & insoluble & 1.5691 \\
\hline Atrazine-d5 & $163165-75-1$ & 220.71 & 2.63 & $1.05009 \mathrm{E}-10$ & 200 & $171-174$ & - & 1.3 \\
\hline Atrazine & $1912-24-9$ & 215.68 & 2.61 & 3.79344E-10 & 200 & 175 & 70 & 1.187 \\
\hline Methiamitron & $41394-05-2$ & 202.21 & 0.83 & $8.46632 \mathrm{E}-12$ & 340.33 & $167-170$ & $1800^{\mathrm{a}}$ & 1.2165 \\
\hline
\end{tabular}




\begin{tabular}{|c|c|c|c|c|c|c|c|c|}
\hline$\beta-\mathrm{BHC}$ & $319-85-7$ & 290.83 & 3.72 & 5.90674E-08 & 373.64 & $>300$ & 0.24 & 1.9 \\
\hline Quintozene & $82-68-8$ & 295.33 & 4.22 & $6.56304 \mathrm{E}-08$ & 328 & 146 & insoluble & 1.718 \\
\hline$\gamma$-BHC-d6 & $60556-82-3$ & 296.9 & 3.64 & - & - & - & - & - \\
\hline$\gamma-\mathrm{BHC}$ & $58-89-9$ & 290.83 & 3.72 & $5.90674 \mathrm{E}-08$ & 373.64 & $113-115$ & 7.3 & 1.7152 \\
\hline Propyzamide-d3 (phenyl-2,4,6-d3) & $1219805-79-4$ & 259.14 & 3.64 & $9.18826 \mathrm{E}-08$ & 340.9 & - & - & 1.3 \\
\hline Propyzamide & $23950-58-5$ & 256.13 & 3.43 & $1.08946 \mathrm{E}-07$ & 340.9 & $153-155$ & 15 & 1.2742 \\
\hline Diazinon-d10 & $100155-47-3$ & 314.41 & 3.81 & $9.28014 \mathrm{E}-08$ & 353.9 & - & - & 1.15 \\
\hline Diazinon & $333-41-5$ & 304.35 & 3.81 & $1.18266 \mathrm{E}-07$ & 306 & $>120$ & 40 & 1.117 \\
\hline Phenanthrene-d10 & $1517-22-2$ & 188.29 & 4.5 & - & 340 & $98-100$ & - & 1.122 \\
\hline Phenanthrene & $85-01-8$ & 178.23 & 4.46 & $1.58826 \mathrm{E}-07$ & 340 & $98-100$ & insoluble & 1.063 \\
\hline Anthracene & $120-12-7$ & 178.23 & 4.45 & 8.61071E-09 & 340 & 215 & 0.045 & 1.28 \\
\hline Etrimfos & $38260-54-7$ & 292.29 & 3.2 & $1.01596 \mathrm{E}-07$ & 77 & -3.35 & $40^{\mathrm{a}}$ & 1.195 \\
\hline$\delta$-BHC & $319-86-8$ & 290.83 & 3.72 & $5.90674 \mathrm{E}-08$ & 373.64 & $113-115$ & insoluble & 1.7152 \\
\hline Benoxacor & $98730-04-2$ & 260.12 & 2.7 & $8.89948 \mathrm{E}-10$ & 240 & $105-107$ & insoluble & 1.3416 \\
\hline DiBP & $84-69-5$ & 278.34 & 4.11 & $6.24801 \mathrm{E}-08$ & 327 & -64 & insoluble & 1.039 \\
\hline Acetochlor-d11 & $1189897-44-6$ & 280.83 & - & - & - & - & - & - \\
\hline Acetochlor & $34256-82-1$ & 269.77 & 4.14 & $3.22902 \mathrm{E}-09$ & 391.05 & $<0^{\circ} \mathrm{C}$ & 223 & 1.1 \\
\hline Chlorpyrifos-methyl & $5598-13-0$ & 322.53 & 4.31 & 2.95337E-08 & 347.3 & $45.5-46.5$ & 4 & 1.64 \\
\hline${ }^{13} \mathrm{C}_{12}-\mathrm{PCB}-28$ & - & - & - & - & - & - & - & - \\
\hline PCB-28 & $7012-37-5$ & 257.54 & 5.62 & $2.55959 \mathrm{E}-07$ & 334.36 & 206-207 & 0.116 & 1.351 \\
\hline ParathionMethyl & $298-00-0$ & 263.21 & 2.86 & 4.59413E-09 & 334.7 & 36 & insoluble & 1.36 \\
\hline Heptachlor & $76-44-8$ & 373.32 & 6.1 & $5.25043 \mathrm{E}-07$ & $134-145$ & $95-96$ & insoluble & 1.57 \\
\hline Ametryn & $834-12-8$ & 227.33 & 2.98 & 3.59655E-09 & 310.44 & $84-85$ & 209 & 1.1232 \\
\hline Prometryn & $7287-19-6$ & 241.36 & 3.51 & 1.62763E-09 & 309.64 & $118-120$ & $48.27^{\mathrm{a}}$ & 1.157 \\
\hline PirimiphosMethyl & 29232-93-7 & 305.33 & 4.12 & $1.96891 \mathrm{E}-08$ & 386.5 & 15 & $9.9^{\mathrm{c}}$ & 1.157 \\
\hline Fenitrothion & $122-14-5$ & 277.23 & 3.3 & $7.08808 \mathrm{E}-08$ & $140-145$ & 3.4 & 30 & 1.3277 \\
\hline
\end{tabular}




\begin{tabular}{|c|c|c|c|c|c|c|c|c|}
\hline${ }^{13} \mathrm{C}_{12}-\mathrm{PCB}-52$ & - & - & - & - & - & - & - & - \\
\hline PCB-52 & $35693-99-3$ & 291.99 & 6.09 & $1.68014 \mathrm{E}-07$ & 374.95 & 87 & 0.1095 & 1.442 \\
\hline DnBP & $84-74-2$ & 278.34 & 4.5 & 2.63834E-08 & 340 & -35 & 13 & 1.043 \\
\hline Malathion-d10 & $347841-48-9$ & 340.4 & - & - & - & - & - & - \\
\hline Malathion & $121-75-5$ & 330.36 & 2.36 & $5.21105 \mathrm{E}-08$ & 385.1 & 2.85 & 145 & 1.3 \\
\hline Diethyl-d10 & 285138-81-0 & 360.65 & 5.3 & - & 375.9 & $44-45$ & - & 1.523 \\
\hline Metolachlor & $51218-45-2$ & 283.79 & 3.13 & 4.12159E-08 & 100 & 25 & $529.7^{\mathrm{a}}$ & 1.12 \\
\hline Aldrin & $309-00-2$ & 364.91 & 6.5 & $1.57513 \mathrm{E}-07$ & $132-150$ & 104 & insoluble & 1.56 \\
\hline Cyanazine & $21725-46-2$ & 240.69 & 2.22 & $1.8114 \mathrm{E}-10$ & 383.12 & 167 & 171 & 1.287 \\
\hline Fenthion-d6 & $1189662-83-6$ & 284.4 & 4.1 & - & - & - & - & - \\
\hline PirimiphosEthyl & 23505-41-1 & 333.39 & 5 & $3.80656 \mathrm{E}-07$ & 414 & $15-18$ & $3.967^{\mathrm{a}}$ & 1.14 \\
\hline Heptachlor Epoxide (Isomer B) & $1024-57-3$ & 389.32 & 5.4 & $3.41278 \mathrm{E}-09$ & 503.92 & $160-161$ & 0.275 & 1.7335 \\
\hline Isofenphos & 25311-71-1 & 345.39 & 4.12 & $3.93782 \mathrm{E}-09$ & 411.5 & $<12$ & $18^{\mathrm{a}}$ & 1.131 \\
\hline Chlorfenvinphos & $470-90-6$ & 359.57 & 3.1 & $5.52608 \mathrm{E}-09$ & $165-167$ & $19-23$ & 145 & 1.373 \\
\hline Phenthoate & $2597-03-7$ & 320.37 & 3.69 & $3.41278 \mathrm{E}-09$ & 379.5 & 156 & 11 & 1.226 \\
\hline Quinalphos & $13593-03-8$ & 298.3 & 4.44 & $3.41278 \mathrm{E}-09$ & 142 & 31.5 & $17.8^{\mathrm{b}}$ & 1.306 \\
\hline Fluoranthene & $206-44-0$ & 202.25 & 5.16 & $1.21022 \mathrm{E}-08$ & 384 & 109 & insoluble & 1.252 \\
\hline Methidathion & $950-37-8$ & 302.33 & 2.2 & 4.42349E-09 & 347.7 & $39-40$ & 240 & 1.51 \\
\hline$o, p^{\prime}-\mathrm{DDE}$ & $3424-82-6$ & 318.03 & 7 & $8.13817 \mathrm{E}-09$ & 403.45 & 78.32 & 0.14 & 1.3406 \\
\hline Tetrachlorvinphos & $2104-64-5$ & 323.3 & 4.78 & $1.24698 \mathrm{E}-09$ & 100 & 36 & insoluble & 1.27 \\
\hline Paclobutrazol & $76738-62-0$ & 293.79 & 3.2 & $9.84456 \mathrm{E}-12$ & 460.9 & $165-166$ & $26^{\mathrm{a}}$ & 1.22 \\
\hline${ }^{13} \mathrm{C}_{12}-\mathrm{PCB}-101$ & - & - & - & - & - & - & - & - \\
\hline PCB-101 & $37680-73-2$ & 326.43 & $6.39^{2}$ & 3.30777E-08 & 412.3 & 78 & 0.011 & 1.522 \\
\hline Butachlor & 23184-66-9 & 311.85 & 4.5 & $3.80656 \mathrm{E}-09$ & 156 & $<-5$ & $20^{\text {a }}$ & 1.0695 \\
\hline$\alpha$-Endosulfan & $959-98-8$ & 406.93 & 8.64 & $8.89948 \mathrm{E}-10$ & 449.7 & 107 & $0.51^{\mathrm{a}}$ & 1.94 \\
\hline Pyrene & $129-00-0$ & 202.25 & 4.88 & $5.90674 \mathrm{E}-09$ & 393 & 148 & insoluble & 1.271 \\
\hline
\end{tabular}




\begin{tabular}{|c|c|c|c|c|c|c|c|c|}
\hline Fenamiphos & $22224-92-6$ & 303.36 & 3.23 & $1.18135 \mathrm{E}-08$ & 375.6 & 49 & 700 & 1.1 \\
\hline Napropamide & $15299-99-7$ & 271.35 & 3.36 & $2.25769 \mathrm{E}-10$ & 414.44 & $73-78$ & $73^{a}$ & 1.0288 \\
\hline Profenofos & $41198-08-7$ & 373.63 & 4.68 & $1.18135 \mathrm{E}-09$ & 110 & $<25$ & 28 & 1.455 \\
\hline$p, p^{\prime}-\mathrm{DDE}$ & $72-55-9$ & 318.03 & 6.51 & 7.87565E-09 & 403.45 & $88-90$ & 292 & 1.3406 \\
\hline Oxadiazon & $19666-30-9$ & 345.22 & 4.8 & $1.5095 \mathrm{E}-10$ & 417 & $88-90$ & 0.7 & 1.413 \\
\hline Dieldrin & $60-57-1$ & 380.91 & 5.4 & $7.73126 \mathrm{E}-09$ & 416.15 & $175-176$ & insoluble & 1.849 \\
\hline$o, p^{\prime}-\mathrm{DDD}$ & $53-19-0$ & 320.04 & 5.87 & $2.54646 \mathrm{E}-09$ & 405.59 & $77-78$ & $<1000$ & 1.3118 \\
\hline Oxyfluorfen & $42874-03-3$ & 361.7 & 4.73 & $2.62522 \mathrm{E}-10$ & $>240$ & $83-84$ & 0.117 & 1.35 \\
\hline Nitrofen & $1836-75-5$ & 284.09 & 4.64 & $1.04365 \mathrm{E}-08$ & 368 & $69-70$ & $1^{b}$ & 1.3 \\
\hline Endrin & $72-20-8$ & 380.91 & 5.2 & 3.93782E-09 & - & 245 & insoluble & 1.65 \\
\hline Fluazifop-butyl & $69806-50-4$ & 383.36 & 4.5 & $4.20035 \mathrm{E}-10$ & 167 & 13 & 0.5366 & 1.21 \\
\hline${ }^{13} \mathrm{C}_{12}-\mathrm{PCB}-118$ & - & - & - & - & - & - & - & - \\
\hline PCB-118 & $31508-00-6$ & 326.43 & 7.12 & $1.17741 \mathrm{E}-08$ & 412.3 & 107 & $0.01344^{\mathrm{a}}$ & 1.522 \\
\hline$\beta$-Endosulfan & $33213-65-9$ & 406.93 & 8.64 & 8.89948E-10 & 449.7 & 209 & 0.28 & 1.6568 \\
\hline PBDE-28 & $41318-75-6$ & 406.89 & 5.94 & $8.79447 \mathrm{E}-10$ & 370 & $64-64.5$ & insoluble & 1.95 \\
\hline Ethion-d20 & $129318188^{\#}$ & 404.6 & 5.1 & - & - & - & - & - \\
\hline Ethion & $563-12-2$ & 384.45 & 5.073 & 1.96891E-09 & 125 & $-12 \sim-15$ & - & 1.22 \\
\hline$p, p^{\prime}-\mathrm{DDD}$ & $72-54-8$ & 256.13 & 3.43 & 1.11572E-07 & 340.9 & $153-155$ & 15 & 1.2742 \\
\hline$o, p^{\prime}-\mathrm{DDT}$ & $789-02-6$ & 354.49 & 9.45 & $1.77202 \mathrm{E}-09$ & 440.74 & 76 & 0.085 & 1.3938 \\
\hline${ }^{13} \mathrm{C}_{12}-\mathrm{PCB}-138$ & - & - & - & - & - & - & - & - \\
\hline PCB-138 & $35065-28-2$ & 360.88 & 7.44 & 4.97478E-09 & 446.99 & 80 & $0.00729^{a}$ & 1.594 \\
\hline BBP & $85-68-7$ & 312.36 & 4.73 & $1.0829 \mathrm{E}-08$ & 370 & $<-35$ & 2.69 & 1.1 \\
\hline${ }^{13} \mathrm{C}_{12^{-}} p, p^{\prime}-\mathrm{DDT}$ & $104215-84-1$ & 366.4 & 6.9 & - & - & - & - & - \\
\hline$p, p^{\prime}-\mathrm{DDT}$ & $50-29-3$ & 354.49 & 6.91 & $2.10017 \mathrm{E}-10$ & 440.74 & $107-110$ & insoluble & 1.556 \\
\hline${ }^{13} \mathrm{C}_{12}-\mathrm{PCB}-153$ & - & - & - & - & - & - & - & - \\
\hline
\end{tabular}




\begin{tabular}{|c|c|c|c|c|c|c|c|c|}
\hline PCB-153 & $35065-27-1$ & 360.88 & 9.73 & $4.50225 \mathrm{E}-08$ & 446.99 & $137-138$ & 0.000863 & 1.594 \\
\hline Pyridaphenthion & $119-12-0$ & 340.33 & 3.2 & $1.44387 \mathrm{E}-11$ & 416.2 & $54.5-56.5$ & $100^{\mathrm{a}}$ & 1.3 \\
\hline Bifenthrin & $82657-04-3$ & 422.87 & 6 & $2.36269 \mathrm{E}-10$ & 453.2 & $68-71$ & 100 & 1.212 \\
\hline Benzo(a)anthracene & $56-55-3$ & 228.29 & 5.76 & $2.75648 \mathrm{E}-10$ & 437.6 & $157-159$ & 0.0094 & 1.274 \\
\hline Fenpropathrin & $39515-41-8$ & 349.42 & 6 & 7.19309E-09 & 448.2 & $45-50$ & 0.33 & 1.15 \\
\hline Chrysene & $218-01-9$ & 228.29 & 5.73 & $8.17755 \mathrm{E}-12$ & 448 & $252-254$ & insoluble & 1.274 \\
\hline${ }^{13} \mathrm{C}_{12}-\mathrm{PCB}-180$ & - & - & - & - & - & - & - & - \\
\hline PCB-180 & $35065-29-3$ & 395.32 & 9.88 & $1.28242 \mathrm{E}-09$ & 479.43 & 114 & $0.00385^{\mathrm{a}}$ & 1.64 \\
\hline DEHP-d4 & $93951-87-2$ & 394.58 & 7.4 & - & 231 & -50 & - & 0.996 \\
\hline DEHP & $117-81-7$ & 390.56 & 7.6 & $1.8639 \mathrm{E}-10$ & 386 & -50 & insoluble & 0.985 \\
\hline Phosalone & $2310-17-0$ & 367.81 & 4.38 & $5.95924 \mathrm{E}-11$ & 446.7 & 47.5 & 3.05 & 1.39 \\
\hline PBDE-47 & $5436-43-1$ & 485.79 & 6.81 & $9.18826 \mathrm{E}-11$ & 396 & $82-82.5$ & insoluble & 2.161 \\
\hline Fenpropathrin-d5 & - & - & - & - & - & - & - & - \\
\hline Delta-Cyhalothrin & $68085-85-8$ & 449.85 & 6.8 & $1.44387 \mathrm{E}-09$ & $187-190$ & $<10$ & $0.004^{\mathrm{a}}$ & 1.25 \\
\hline${ }^{13} \mathrm{C}_{12}$-PBDE-77 & - & - & - & - & - & - & - & - \\
\hline Permethrin & $52645-53-1$ & 391.29 & 6.5 & $6.79931 \mathrm{E}-11$ & 220 & $34-35$ & insoluble & 1.19 \\
\hline Coumaphos-d10 & $10643059^{\#}$ & 372.8 & - & - & - & - & - & - \\
\hline Coumaphos & $56-72-4$ & 362.77 & 4.13 & $1.27323 \mathrm{E}-10$ & 449.9 & 91 & 0.0015 & 1.474 \\
\hline PBDE-100 & $189084-64-8$ & 564.7 & 7.24 & $1.25617 \mathrm{E}-09$ & 434 & $97-98$ & $0.0009^{\mathrm{a}}$ & 2.343 \\
\hline DNOP & $117-84-0$ & 390.56 & 8.1 & $1.31261 \mathrm{E}-10$ & 380 & -25 & insoluble & 0.98 \\
\hline PBDE-99 & $60348-60-9$ & 564.7 & 6.84 & $4.59413 \mathrm{E}-10$ & $200-300$ & -5 & 0.0133 & $2.25-2.28$ \\
\hline Benzo(b)fluoranthene & $205-99-2$ & 252.31 & 5.78 & $6.56304 \mathrm{E}-10$ & 481 & $163-165$ & 0.0012 & 1.1549 \\
\hline Cyfluthrin & $68359-37-5$ & 434.29 & 5.95 & $1.96891 \mathrm{E}-13$ & 496.3 & 60 & $0.002-0.003^{\mathrm{a}}$ & 1.3336 \\
\hline Benzo(k)fluoranthene & $207-08-9$ & 252.31 & 6.11 & $1.26667 \mathrm{E}-12$ & 480 & $215-217$ & 0.00109 & 1.286 \\
\hline Cypermethrin & $52315-07-8$ & 416.3 & 6.6 & $2.23143 \mathrm{E}-12$ & $170-195$ & $60-80$ & insoluble & 1.12 \\
\hline Benzo(a)pyrene & $50-32-8$ & 252.31 & 6.13 & $7.20622 \mathrm{E}-12$ & 495 & $177-181$ & insoluble & 1.1549 \\
\hline
\end{tabular}




\begin{tabular}{lllllllll} 
Perylene-d12 & $1520-96-3$ & 264.38 & 5.8 & - & 467.5 & $277-279$ & insoluble & 1.3 \\
Fenvalerate & $51630-58-1$ & 419.9 & 6.2 & $1.96891 \mathrm{E}-12$ & 300 & $54-59$ & $10^{\text {a }}$ & 1.17 \\
PBDE-153 & $68631-49-2$ & 643.6 & 7.9 & 0.001443869 & 453 & 157.6 & insoluble & 2.502 \\
Deltamethrin & $52918-63-5$ & 505.2 & 6.2 & $1.22073 \mathrm{E}-13$ & 300 & 98 & $<0.0002$ & 1.5214 \\
Indeno(1,2,3-cd)pyrene & $193-39-5$ & 276.33 & 6.7 & $1.64076 \mathrm{E}-13$ & 536 & 164 & 0.062 & 1.1847 \\
Dibenz(a,h)anthracene & $53-70-3$ & 278.35 & 6.5 & $1.25354 \mathrm{E}-12$ & 524 & $262-265$ & 0.0022 & 1.282 \\
Benzo(g,h,i)perylene & $191-24-2$ & 276.33 & 6.63 & $1.31261 \mathrm{E}-13$ & $>500$ & $277-279$ & 0.000137 & 1.1847 \\
\hline
\end{tabular}

*a means relative density under $20^{\circ} \mathrm{C}$

*b means relative density under $22.5^{\circ} \mathrm{C}$

$*^{*}$ c means relative density under $30^{\circ} \mathrm{C}$

*\# means PubChem CID 
Table S2. The full name and abbreviation pairs of priority pollutants including 16 PAHs, 5 PBDEs, 7 PAEs and 7 PCBs.

\begin{tabular}{|c|c|c|c|}
\hline Full name & Abbreviation & Full name & Abbreviation \\
\hline Naphthalene & Nap & 2.2'4.4'.5- Pentabromodiphenyl ether & PBDE-99 \\
\hline Acenaphthylene & Acel & 2.2'4.4'.6- Pentabromodiphenyl ether & PBDE-100 \\
\hline Acenaphthene & Ace & 2.2'.4.4'.5.5'-Hexabromodiphenyl ether & PBDE-153 \\
\hline Fluorene & Flu & Dimethyl phthalate & DMP \\
\hline Phenanthrene & Phe & Diethyl phthalate & DEP \\
\hline Anthracene & Ant & Di-isobutyl phthalate & DiBP \\
\hline Fluoranthene & Fla & Di-n-butyl phthalate & DnBP \\
\hline Pyrene & Pyr & Benzyl butyl phthalate & BBP \\
\hline Benzo(a)anthracene & $\mathrm{BaA}$ & Di(2-ethylhexyl) Phthalate & DEHP \\
\hline Chrysene & Chry & Di-n-octyl phthalate & DNOP \\
\hline Benzo(b)fluoranthene & $\mathrm{BbF}$ & 2,4,4'-Trichlorobiphenyl & PCB-28 \\
\hline Benzo(k)fluoranthene & $\mathrm{BkF}$ & 2,2',5,5'-Tetrachlorobiphenyl & PCB-52 \\
\hline Benzo(a)pyrene & $\mathrm{BaP}$ & 2,2',4,5,5'-Pentachlorobiphenyl & PCB-101 \\
\hline Indeno(1,2,3-cd)pyrene & IcdP & 2,3',4,4',5-pentachlorobiphenyl & PCB-118 \\
\hline Dibenz(a,h)anthracene & DahA & 2,2',3,4,4',5'-Hexachlorobiphenyl & PCB-138 \\
\hline Benzo(g,h,i)perylene & BghiP & 2,2',4,4',5,5'-hexachlorobiphenyl & PCB-153 \\
\hline 2,4,4-Tribromodiphenyl Ether & PBDE-28 & $2,2^{\prime}, 3,4,4^{\prime}, 5,5^{\prime}-$ Heptachlorobiphenyl & PCB-180 \\
\hline 2,2',4,4'-Tetrabromodiphenylether & PBDE-47 & & \\
\hline
\end{tabular}


Table S3. Studied SVOCs, CAS number, retention time, and MRM transitions (m/z).

\begin{tabular}{|c|c|c|c|c|c|c|c|c|c|c|c|c|}
\hline \multirow[b]{2}{*}{ Compounds } & \multirow[b]{2}{*}{ CAS number } & \multirow[b]{2}{*}{ Chemical family } & \multirow{2}{*}{$\begin{array}{l}\text { RT } \\
\text { Window } \\
(\min )\end{array}$} & \multirow{2}{*}{$\begin{array}{l}\text { Scan } \\
\text { Time } \\
\text { (ms) }\end{array}$} & \multirow{2}{*}{$\begin{array}{l}\mathrm{tR} \\
(\mathrm{min})\end{array}$} & \multicolumn{3}{|c|}{ MRM transition 1} & \multicolumn{3}{|c|}{ MRM transition 2} & \multirow[b]{2}{*}{ IS } \\
\hline & & & & & & $\begin{array}{l}\text { Precusor } \\
\text { ion }\end{array}$ & $\begin{array}{l}\text { Product } \\
\text { ion }\end{array}$ & $\begin{array}{l}\text { Collision } \\
\text { energy(V) }\end{array}$ & $\begin{array}{l}\text { Precusor } \\
\text { ion }\end{array}$ & $\begin{array}{l}\text { Product } \\
\text { ion }\end{array}$ & $\begin{array}{l}\text { Collision } \\
\text { energy (V) }\end{array}$ & \\
\hline Naphthalene-d8 & $1146-65-2$ & PAHs & 0.50 & 50 & 6.13 & 136.1 & 108 & 22 & 429.5 & 394.7 & 10 & - \\
\hline Naphthalene & $91-20-3$ & PAHs & 0.50 & 50 & 6.17 & 128 & 102 & 22 & 350.8 & 260.8 & 5 & Naphthalene-d8 \\
\hline Dichlorvos-d6 & $203645-53-8$ & Organophosphate & 0.50 & 50 & 6.71 & 114.8 & 83.1 & 10 & 190.7 & 99.1 & 15 & - \\
\hline Dichlorvos & $62-73-7$ & Organophosphate & 0.50 & 50 & 6.74 & 109 & 79 & 10 & 185 & 93 & 15 & Dichlorvos-d6 \\
\hline Mevinphos & $7786-34-7$ & Organophosphate & 0.50 & 33 & 9.54 & 127 & 109 & 10 & 192 & 127 & 15 & Dichlorvos-d6 \\
\hline DMP & $131-11-3$ & PAEs & 0.50 & 33 & 9.89 & 163 & 132 & 5 & 163 & 77 & 15 & DEP-d4 \\
\hline Propham & $122-42-9$ & Herbicides & 0.50 & 33 & 10.03 & 179 & 93 & 15 & 179 & 137 & 5 & Atrazine-d5 \\
\hline Acenaphthylene & $208-96-8$ & PAHs & 0.50 & 33 & 10.08 & 152.1 & 151 & 10 & 152.1 & 150 & 25 & Naphthalene-d8 \\
\hline Acenaphthene & $83-32-9$ & PAHs & 0.50 & 33 & 10.51 & 153.1 & 152 & 10 & 153.1 & 151 & 20 & Naphthalene-d8 \\
\hline DEP-d4 & $93952-12-6$ & PAEs & 0.50 & 33 & 11.63 & 153 & 69.1 & 15 & 181 & 153 & 5 & - \\
\hline DEP & $84-66-2$ & PAEs & 0.50 & 33 & 11.65 & 149 & 65.1 & 15 & 177 & 149 & 5 & DEP-d4 \\
\hline Fluorene & $86-73-7$ & PAHs & 0.50 & 33 & 11.77 & 166.2 & 165 & 5 & 166.2 & 139 & 45 & Naphthalene-d8 \\
\hline Ethoprophos & $13194-48-4$ & Organophosphate & 0.50 & 25 & 12.22 & 158 & 97 & 18 & 200 & 158 & 5 & Dichlorvos-d6 \\
\hline Trifluralin & $1582-09-8$ & Herbicides & 0.50 & 16 & 12.59 & 306 & 264 & 5 & 306 & 206 & 15 & Atrazine-d5 \\
\hline Phorate & $298-02-2$ & Organophosphate & 0.50 & 16 & 12.9 & 121 & 65 & 10 & 260 & 175 & 10 & Dichlorvos-d6 \\
\hline$\alpha-\mathrm{BHC}$ & $319-84-6$ & Organochlorine & 0.50 & 16 & 13.08 & 181 & 145 & 10 & 219 & 183 & 5 & $\gamma$-BHC-d6 \\
\hline${ }^{13} \mathrm{C}_{6}$-Hexachlorobenzene & $93952-14-8$ & Organochlorine & 0.50 & 20 & 13.15 & 289.5 & 254.9 & 30 & 254.5 & 219.8 & 30 & - \\
\hline Hexachlorobenzene & $118-74-1$ & Organochlorine & 0.50 & 20 & 13.18 & 286 & 214 & 35 & 282 & 212 & 30 & ${ }^{13} \mathrm{C}_{6}$-Hexachlorobenzene \\
\hline Atrazine-d5 & $163165-75-1$ & Herbicides & 0.50 & 11 & 13.67 & 204.6 & 105.1 & 5 & 219.6 & 205.1 & 10 & - \\
\hline Atrazine & $1912-24-9$ & Herbicides & 0.50 & 11 & 13.71 & 200 & 122 & 5 & 215 & 172 & 15 & Atrazine-d5 \\
\hline Methiamitron & $41394-05-2$ & Herbicides & 0.50 & 11 & 13.73 & 104 & 62 & 15 & 202 & 122 & 5 & Atrazine-d5 \\
\hline$\beta$-BHC & $319-85-7$ & Organochlorine & 0.50 & 11 & 13.74 & 181 & 145 & 10 & 219 & 183 & 10 & $\gamma$-BHC-d6 \\
\hline
\end{tabular}




\begin{tabular}{|c|c|c|c|c|c|c|c|c|c|c|c|c|}
\hline Quintozene & $82-68-8$ & Organochlorine & 0.50 & 11 & 13.76 & 295 & 237 & 18 & 295 & 265 & 10 & ${ }^{13} \mathrm{C}_{6}$-Hexachlorobenzene \\
\hline$\gamma$-BHC-d6 & $60556-82-3$ & Organochlorine & 0.50 & 11 & 13.81 & 225 & 189 & 10 & 223 & 187 & 10 & - \\
\hline$\gamma$-BHC & $58-89-9$ & Organochlorine & 0.50 & 11 & 13.83 & 181 & 145 & 10 & 219 & 183 & 10 & $\gamma$-BHC-d6 \\
\hline $\begin{array}{l}\text { Propyzamide-d3 (phenyl- } \\
\text { 2,4,6-d3) }\end{array}$ & $1219805-79-4$ & Herbicides & 0.50 & 11 & 14.10 & 176 & 112 & 25 & 257.1 & 229 & 10 & - \\
\hline Propyzamide & $23950-58-5$ & Herbicides & 0.50 & 11 & 14.13 & 173 & 109 & 25 & 254 & 226 & 5 & $\begin{array}{l}\text { Propyzamide-d3 } \\
\text { (phenyl-2,4,6-d3) }\end{array}$ \\
\hline Diazinon-d10 & $100155-47-3$ & Organophosphate & 0.50 & 11 & 14.15 & 182.6 & 168.2 & 10 & 137.7 & 85.2 & 10 & - \\
\hline Diazinon & $333-41-5$ & Organophosphate & 0.50 & 11 & 14.17 & 137 & 84 & 10 & 304 & 179 & 10 & Diazinon-d10 \\
\hline Phenanthrene-d10 & $1517-22-2$ & PAHs & 0.50 & 11 & 14.22 & 188.2 & 160 & 15 & 188.2 & 186 & 15 & - \\
\hline Phenanthrene & $85-01-8$ & PAHs & 0.50 & 12 & 14.29 & 178.1 & 152 & 15 & 178.1 & 176 & 20 & Phenanthrene-d 10 \\
\hline Anthracene & $120-12-7$ & PAHs & 0.50 & 12 & 14.44 & 178.1 & 152 & 15 & 178.1 & 176 & 20 & Phenanthrene-d 10 \\
\hline Etrimfos & $38260-54-7$ & Organophosphate & 0.50 & 12 & 14.56 & 181 & 153 & 10 & 292 & 181 & 10 & Diazinon-d10 \\
\hline$\delta$-BHC & $319-86-8$ & Organochlorine & 0.50 & 12 & 14.61 & 181 & 145 & 10 & 219 & 183 & 10 & $\gamma$-BHC-d6 \\
\hline Benoxacor & $98730-04-2$ & Herbicides & 0.50 & 20 & 14.88 & 120 & 65 & 20 & 259 & 120 & 20 & $\begin{array}{l}\text { Propyzamide-d3 } \\
\text { (phenyl-2,4,6-d3) }\end{array}$ \\
\hline DiBP & $84-69-5$ & PAEs & 0.50 & 16 & 15.05 & 149 & 65.1 & 15 & 223 & 149 & 5 & DEP-d4 \\
\hline Acetochlor-d11 & $1189897-44-6$ & Herbicides & 0.50 & 14 & 15.26 & 172.7 & 155.1 & 20 & 232.6 & 139.2 & 25 & - \\
\hline Acetochlor & $34256-82-1$ & Herbicides & 0.50 & 14 & 15.29 & 146 & 130 & 25 & 223 & 132 & 20 & Acetochlor-d11 \\
\hline Chlorpyrifos-methyl & $5598-13-0$ & Organophosphate & 0.50 & 14 & 15.32 & 125 & 47 & 15 & 286 & 271 & 15 & Diazinon-d10 \\
\hline${ }^{13} \mathrm{C}_{12}-\mathrm{PCB}-28$ & & $\mathrm{PCBs}$ & 0.50 & 14 & 15.36 & 268 & 163 & 60 & 268 & 198 & 25 & - \\
\hline PCB-28 & $7012-37-5$ & PCBs & 0.50 & 14 & 15.38 & 256 & 186 & 25 & 256 & 151 & 60 & ${ }^{13} \mathrm{C}_{12}-\mathrm{PCB}-28$ \\
\hline ParathionMethyl & $298-00-0$ & Organophosphate & 0.50 & 14 & 15.48 & 109 & 79 & 10 & 263 & 109 & 15 & Diazinon-d10 \\
\hline Heptachlor & $76-44-8$ & Organochlorine & 0.50 & 14 & 15.66 & 272 & 237 & 15 & 272 & 141 & 30 & $\begin{array}{l}\text { Heptachlor } \\
\text { (Isomer B) }\end{array}$ \\
\hline Ametryn & $834-12-8$ & Herbicides & 0.50 & 14 & 15.72 & 227 & 185 & 5 & 227 & 212 & 5 & Acetochlor-d11 \\
\hline
\end{tabular}




\begin{tabular}{|c|c|c|c|c|c|c|c|c|c|c|c|c|}
\hline Prometryn & $7287-19-6$ & Herbicides & 0.50 & 14 & 15.79 & 241 & 184 & 5 & 242 & 199 & 10 & Acetochlor-d11 \\
\hline PirimiphosMethyl & 29232-93-7 & Organophosphate & 0.50 & 10 & 16.04 & 290 & 233 & 10 & 276 & 151 & 15 & Malathion-d10 \\
\hline Fenitrothion & $122-14-5$ & Organophosphate & 0.50 & 10 & 16.11 & 277 & 260 & 10 & 260 & 125 & 15 & Malathion-d10 \\
\hline${ }^{13} \mathrm{C}_{12}$-PCB-52 & & PCBs & 0.50 & 10 & 16.2 & 304 & 234 & 30 & 304 & 269 & 10 & - \\
\hline PCB-52 & $35693-99-3$ & PCBs & 0.50 & 10 & 16.22 & 292 & 222 & 30 & 292 & 257 & 15 & ${ }^{13} \mathrm{C}_{12}-\mathrm{PCB}-52$ \\
\hline DnBP & $84-74-2$ & PAEs & 0.50 & 10 & 16.25 & 149 & 65.1 & 15 & 223 & 149 & 5 & DEP-d4 \\
\hline Malathion-d10 & $347841-48-9$ & Organophosphate & 0.50 & 10 & 16.31 & 182.8 & 100.1 & 20 & 131.8 & 100.2 & 15 & - \\
\hline Malathion & $121-75-5$ & Organophosphate & 0.50 & 10 & 16.33 & 125 & 79 & 10 & 173 & 99 & 18 & Malathion-d10 \\
\hline Diethyl-d10 & $285138-81-0$ & Organophosphate & 0.50 & 10 & 16.41 & 324 & 260 & 11 & 324 & 292 & 9 & - \\
\hline Metolachlor & $51218-45-2$ & Herbicides & 0.50 & 10 & 16.45 & 162 & 133 & 15 & 238 & 162 & 5 & Diethyl-d10 \\
\hline Aldrin & $309-00-2$ & Organochlorine & 0.50 & 10 & 16.56 & 263 & 193 & 25 & 263 & 228 & 20 & $\begin{array}{l}\text { Heptachlor } \\
\text { (Isomer B) }\end{array}$ \\
\hline Cyanazine & $21725-46-2$ & Herbicides & 0.50 & 10 & 16.67 & 225 & 189 & 15 & 225 & 172 & 15 & Diethyl-d10 \\
\hline Fenthion-d6 & $1189662-83-6$ & Organophosphate & 0.50 & 16 & 16.78 & 283.5 & 169 & 10 & 130.8 & 50.2 & 20 & - \\
\hline PirimiphosEthyl & $23505-41-1$ & Organophosphate & 0.50 & 16 & 17.06 & 333 & 180 & 5 & 333 & 168 & 25 & Fenthion-d6 \\
\hline $\begin{array}{l}\text { Heptachlor } \quad \text { Epoxide } \\
\text { (Isomer B) }\end{array}$ & $1024-57-3$ & Organochlorine & 0.50 & 16 & 17.54 & 353 & 263 & 15 & 353 & 282 & 15 & - \\
\hline Isofenphos & $25311-71-1$ & Organophosphate & 0.50 & 16 & 17.57 & 185 & 121 & 10 & 213 & 185 & 15 & Fenthion-d6 \\
\hline Chlorfenvinphos & $470-90-6$ & Organochlorine & 0.50 & 16 & 17.62 & 267 & 159 & 20 & 323 & 267 & 15 & $\begin{array}{l}\text { Heptachlor } \\
\text { (Isomer B) }\end{array}$ \\
\hline Phenthoate & $2597-03-7$ & Organophosphate & 0.50 & 16 & 17.74 & 246 & 121 & 15 & 274 & 125 & 18 & Fenthion-d6 \\
\hline Quinalphos & $13593-03-8$ & Organophosphate & 0.50 & 16 & 17.78 & 146 & 118 & 10 & 298 & 129 & 30 & Fenthion-d6 \\
\hline Fluoranthene & $206-44-0$ & PAHs & 0.50 & 12 & 17.85 & 202.1 & 200 & 40 & 202.1 & 201 & 20 & Phenanthrene-d 10 \\
\hline Methidathion & $950-37-8$ & Organophosphate & 0.50 & 11 & 18.12 & 145 & 85 & 10 & 125 & 79 & 10 & Fenthion-d6 \\
\hline$o, p^{\prime}-\mathrm{DDE}$ & $3424-82-6$ & Organochlorine & 0.50 & 10 & 18.23 & 246 & 176 & 30 & 318 & 248 & 15 & ${ }^{13} \mathrm{C}_{12^{-}}-p, p^{\prime}-\mathrm{DDT}$ \\
\hline Tetrachlorvinphos & $2104-64-5$ & Organophosphate & 0.50 & 10 & 18.29 & 331 & 109 & 15 & 329 & 314 & 20 & Fenthion-d6 \\
\hline
\end{tabular}




\begin{tabular}{|c|c|c|c|c|c|c|c|c|c|c|c|}
\hline Paclobutrazol & $76738-62-0$ & Herbicides & 0.50 & 10 & 18.33 & 236 & 125 & 10 & 236 & 132 & 5 \\
\hline${ }^{13} \mathrm{C}_{12}-\mathrm{PCB}-101$ & - & PCBs & 0.50 & 10 & 18.35 & 337.9 & 268 & 30 & 337.9 & 303 & 15 \\
\hline PCB-101 & $37680-73-2$ & PCBs & 0.50 & 10 & 18.37 & 325.9 & 256 & 30 & 325.9 & 291 & 15 \\
\hline Butachlor & 23184-66-9 & Herbicides & 0.50 & 10 & 18.38 & 176 & 147 & 15 & 237 & 160 & 5 \\
\hline$\alpha$-Endosulfan & $959-98-8$ & Organochlorine & 0.50 & 10 & 18.5 & 241 & 206 & 20 & 265 & 195 & 25 \\
\hline Pyrene & $129-00-0$ & PAHs & 0.50 & 10 & 18.52 & 202.1 & 200 & 40 & 202.1 & 150 & 50 \\
\hline Fenamiphos & $22224-92-6$ & Organophosphate & 0.50 & 10 & 18.69 & 154 & 139 & 10 & 303 & 154 & 18 \\
\hline Napropamide & $15299-99-7$ & Herbicides & 0.50 & 10 & 18.7 & 128 & 72 & 5 & 271 & 128 & 10 \\
\hline Profenofos & 41198-08-7 & Organophosphate & 0.50 & 12 & 18.97 & 139 & 97 & 10 & 339 & 188 & 20 \\
\hline$p, p^{\prime}-\mathrm{DDE}$ & $72-55-9$ & Organochlorine & 0.50 & 12 & 19.08 & 246 & 176 & 30 & 318 & 246 & 15 \\
\hline Oxadiazon & 19666-30-9 & Herbicides & 0.50 & 12 & 19.09 & 175 & 112 & 15 & 258 & 175 & 5 \\
\hline Dieldrin & $60-57-1$ & Organochlorine & 0.50 & 12 & 19.12 & 277 & 241 & 10 & 277 & 206 & 15 \\
\hline$o, p^{\prime}-\mathrm{DDD}$ & $53-19-0$ & Organochlorine & 0.50 & 12 & 19.2 & 235 & 165 & 25 & 235 & 199 & 15 \\
\hline Oxyfluorfen & $42874-03-3$ & Herbicides & 0.50 & 12 & 19.24 & 252 & 146 & 35 & 300 & 132 & 40 \\
\hline Nitrofen & $1836-75-5$ & Herbicides & 0.50 & 12 & 19.7 & 202 & 139 & 25 & 285 & 255 & 5 \\
\hline Endrin & $72-20-8$ & Organochlorine & 0.50 & 12 & 19.71 & 281 & 245 & 10 & 263 & 228 & 20 \\
\hline Fluazifop-butyl & $69806-50-4$ & Herbicides & 0.50 & 12 & 19.72 & 383 & 282 & 15 & 383 & 254 & 30 \\
\hline${ }^{13} \mathrm{C}_{12}-\mathrm{PCB}-118$ & - & $\mathrm{PCBs}$ & 0.50 & 12 & 19.92 & 337.5 & 268 & 30 & 265.5 & 196 & 20 \\
\hline PCB-118 & $31508-00-6$ & PCBs & 0.50 & 12 & 19.95 & 325.9 & 256 & 30 & 325.9 & 291 & 15 \\
\hline$\beta$-Endosulfan & $33213-65-9$ & Organochlorine & 0.50 & 12 & 20.01 & 195 & 159 & 10 & 241 & 206 & 15 \\
\hline PBDE-28 & $41318-75-6$ & PBDEs & 0.50 & 33 & 20.15 & 406 & 246 & 25 & 246 & 139 & 45 \\
\hline Ethion-d20 & - & Organophosphate & 0.50 & 12 & 20.16 & 240.6 & 131 & 20 & 162.7 & 99.1 & 10 \\
\hline
\end{tabular}




\begin{tabular}{|c|c|c|c|c|c|c|c|c|c|c|c|c|}
\hline Ethion & $563-12-2$ & Organophosphate & 0.50 & 12 & 20.17 & 231 & 129 & 20 & 231 & 175 & 10 & Ethion-d20 \\
\hline$p, p^{\prime}-\mathrm{DDD}$ & $72-54-8$ & Organochlorine & 0.50 & 12 & 20.19 & 235 & 165 & 25 & 235 & 200 & 10 & ${ }^{13} \mathrm{C}_{12}-p, p^{\prime}-\mathrm{DDT}$ \\
\hline$o, p^{\prime}-\mathrm{DDT}$ & $789-02-6$ & Organochlorine & 0.50 & 12 & 20.21 & 235 & 165 & 25 & 235 & 199 & 15 & ${ }^{13} \mathrm{C}_{12}-p, p^{\prime}-\mathrm{DDT}$ \\
\hline${ }^{13} \mathrm{C}_{12}$-PCB-138 & & PCBs & 0.50 & 16 & 20.51 & 371.9 & 302 & 30 & 371.9 & 300 & 25 & - \\
\hline PCB-138 & $35065-28-2$ & PCBs & 0.50 & 16 & 20.53 & 359.9 & 290 & 30 & 359.9 & 325 & 15 & ${ }^{13} \mathrm{C}_{12}-\mathrm{PCB}-138$ \\
\hline BBP & $85-68-7$ & PAEs & 0.50 & 25 & 21.16 & 149 & 65.1 & 15 & 206 & 149 & 5 & DEHP-d4 \\
\hline${ }^{13} \mathrm{C}_{12}-\mathrm{p}, \mathrm{p}^{\prime}-\mathrm{DDT}$ & $104215-84-1$ & Organochlorine & 0.50 & 25 & 21.23 & 247 & 211 & 20 & 368 & 247 & 5 & - \\
\hline$p, p^{\prime}-\mathrm{DDT}$ & $50-29-3$ & Organochlorine & 0.50 & 25 & 21.25 & 235 & 165 & 25 & 235 & 199 & 15 & ${ }^{13} \mathrm{C}_{12}-p, p^{\prime}-\mathrm{DDT}$ \\
\hline${ }^{13} \mathrm{C}_{12}$-PCB-153 & & PCBs & 0.50 & 25 & 21.33 & 371.8 & 302 & 32 & 371.8 & 300 & 25 & - \\
\hline PCB-153 & $35065-27-1$ & PCBs & 0.50 & 25 & 21.35 & 359.9 & 290 & 32 & 359.9 & 325 & 15 & ${ }^{13} \mathrm{C}_{12}$-PCB-153 \\
\hline Pyridaphenthion & $119-12-0$ & Organophosphate & 0.50 & 16 & 22.77 & 340 & 199 & 10 & 340 & 109 & 20 & Ethion-d20 \\
\hline Bifenthrin & $82657-04-3$ & Pyrethroid & 0.50 & 16 & 23.24 & 181 & 166 & 10 & 181 & 165 & 25 & Fenpropathrin-d5 \\
\hline Benzo(a)anthracene & $56-55-3$ & PAHs & 0.50 & 16 & 23.25 & 228.1 & 202 & 20 & 228.1 & 226 & 20 & Perylene-d12 \\
\hline Fenpropathrin-d5 & - & Pyrethroid & 0.50 & 20 & 23.39 & 270.1 & 215 & 15 & 186.1 & 132 & 30 & - \\
\hline Fenpropathrin & $39515-41-8$ & Pyrethroid & 0.50 & 20 & 23.43 & 181 & 152 & 20 & 265 & 210 & 10 & Fenpropathrin-d5 \\
\hline Chrysene & 218-01-9 & PAHs & 0.50 & 16 & 23.68 & 228.2 & 202 & 20 & 228.2 & 226 & 20 & Perylene-d12 \\
\hline${ }^{13} \mathrm{C}_{12}$-PCB-180 & & PCBs & 0.50 & 20 & 23.96 & 407.9 & 338 & 32 & 407.9 & 336 & 30 & - \\
\hline PCB-180 & $35065-29-3$ & PCBs & 0.50 & 20 & 24 & 393.9 & 324 & 32 & 393.9 & 359 & 15 & ${ }^{13} \mathrm{C}_{12}-\mathrm{PCB}-180$ \\
\hline DEHP-d4 & $93951-87-2$ & PAEs & 0.50 & 33 & 24.58 & 153 & 69.1 & 15 & 171.1 & 153 & 5 & - \\
\hline DEHP & $117-81-7$ & PAEs & 0.50 & 33 & 24.62 & 149 & 65.1 & 15 & 167 & 149 & 5 & DEHP-d4 \\
\hline Phosalone & $2310-17-0$ & Organophosphate & 0.50 & 33 & 24.75 & 182 & 111 & 15 & 367 & 138 & 30 & Coumaphos-d10 \\
\hline PBDE-47 & $5436-43-1$ & PBDEs & 0.50 & 33 & 25.32 & 486 & 329.5 & 25 & 486 & 219 & 45 & ${ }^{13} \mathrm{C}_{12}$-PBDE-77 \\
\hline Delta-Cyhalothrin & $68085-85-8$ & Pyrethroid & 0.50 & 100 & 25.42 & 181 & 152 & 25 & 197 & 141 & 10 & Fenpropathrin-d5 \\
\hline${ }^{13} \mathrm{C}_{12}$-PBDE-77 & - & PBDEs & 0.50 & 25 & 26.74 & 497.1 & 229.8 & 45 & 221.5 & 149 & 25 & - \\
\hline Permethrin & $52645-53-1$ & Pyrethroid & 0.50 & 25 & 27.42 & 183 & 168 & 10 & 183 & 128 & 20 & Fenpropathrin-d5 \\
\hline Coumaphos-d10 & - & Organophosphate & 0.50 & 33 & 27.43 & 371.5 & 155.1 & 15 & 280.4 & 248.9 & 15 & - \\
\hline
\end{tabular}




\begin{tabular}{|c|c|c|c|c|c|c|c|c|c|c|c|c|}
\hline Coumaphos & $56-72-4$ & Organophosphate & 0.50 & 33 & 27.44 & 362 & 226 & 15 & 362 & 109 & 15 & Coumaphos-d10 \\
\hline PBDE-100 & $189084-64-8$ & PBDEs & 0.50 & 11 & 27.51 & 405.8 & 137 & 50 & 405.8 & 297 & 45 & ${ }^{13} \mathrm{C}_{12}$-PBDE-77 \\
\hline DNOP & $117-84-0$ & PAEs & 0.50 & 25 & 27.69 & 149 & 65.1 & 15 & 279 & 149 & 5 & DEHP-d4 \\
\hline PBDE-99 & $60348-60-9$ & PBDEs & 0.50 & 11 & 28.04 & 405.8 & 137 & 50 & 405.8 & 297 & 45 & ${ }^{13} \mathrm{C}_{12}$-PBDE-77 \\
\hline Benzo(b)fluoranthene & $205-99-2$ & PAHs & 0.50 & 25 & 28.23 & 252.1 & 250 & 20 & 252.1 & 226 & 20 & Perylene-d12 \\
\hline Cyfluthrin & $68359-37-5$ & Pyrethroid & 0.50 & 25 & 28.25 & 226 & 206 & 5 & 206 & 151 & 15 & Fenpropathrin-d5 \\
\hline Benzo(k)fluoranthene & $207-08-9$ & PAHs & 0.50 & 25 & 28.3 & 252.1 & 250 & 20 & 252.1 & 226 & 20 & Perylene-d12 \\
\hline Cypermethrin & $52315-07-8$ & Pyrethroid & 0.50 & 25 & 28.65 & 163 & 127 & 5 & 181 & 152 & 20 & Fenpropathrin-d5 \\
\hline Benzo(a)pyrene & $50-32-8$ & PAHs & 0.50 & 25 & 29.12 & 252.2 & 250 & 50 & 252.2 & 226 & 20 & Perylene-d12 \\
\hline Perylene-d12 & $1520-96-3$ & PAHs & 0.50 & 25 & 29.28 & 264.2 & 260.1 & 30 & 260.1 & 258.1 & 30 & - \\
\hline Fenvalerate & $51630-58-1$ & Pyrethroid & 0.50 & 25 & 29.74 & 181 & 152 & 20 & 225 & 119 & 18 & Fenpropathrin-d5 \\
\hline PBDE-153 & $68631-49-2$ & PBDEs & 0.50 & 14 & 29.81 & 483.7 & 324 & 45 & 483.7 & 377 & 50 & ${ }^{13} \mathrm{C}_{12}-\mathrm{PBDE}-77$ \\
\hline Deltamethrin & $52918-63-5$ & Pyrethroid & 0.50 & 100 & 30.58 & 181 & 152 & 20 & 253 & 199 & 25 & Fenpropathrin-d5 \\
\hline Indeno(1,2,3-cd)pyrene & $193-39-5$ & PAHs & 0.50 & 33 & 31.6 & 276.2 & 274 & 45 & 276.2 & 248 & 60 & Perylene-d12 \\
\hline Dibenz(a,h)anthracene & $53-70-3$ & PAHs & 0.50 & 33 & 31.65 & 278.8 & 276 & 40 & 278.2 & 252 & 35 & Perylene-d12 \\
\hline Benzo(g,h,i)perylene & $191-24-2$ & PAHs & 0.50 & 33 & 32.06 & 276.2 & 274 & 45 & 276.2 & 248 & 60 & Perylene-d12 \\
\hline
\end{tabular}

* The scan time was automatic calculated relied on the compute scan times function module based on the parameters as follows: peak width equal to 1.0 and point per peak was 10. Besides, the retention windows of all the analytes was $0.5 \mathrm{~min}$ and the collect delay time was $4.0 \mathrm{~min}$. 
Table S4. Optimal instrumental configuration and conditions.

\begin{tabular}{|c|c|c|c|c|c|}
\hline \multicolumn{6}{|c|}{ Configuration and conditions } \\
\hline \multicolumn{4}{|c|}{ Bruker 456-GC gas chromatograph } & \multicolumn{2}{|c|}{ Bruker SCION TQ triple quad mass spectrometer } \\
\hline \multirow{6}{*}{\multicolumn{2}{|c|}{$\begin{array}{l}\text { DB-5 MS capillary column } \\
\text { carrier gas } \\
\text { flow rate } \\
\text { injection mode } \\
\text { injector temperature } \\
\text { transfer line temperature }\end{array}$}} & \multicolumn{2}{|c|}{$30 \mathrm{~m} \times 0.25 \mathrm{~mm} \mathrm{ID}, 0.25 \mu \mathrm{m}$} & ionization source & electron impact (EI) \\
\hline & & \multicolumn{2}{|c|}{ helium (>99.999\%) } & ion energy & $70 \mathrm{eV}$ \\
\hline & & \multicolumn{2}{|c|}{$1.0 \mathrm{~mL} \min -1$} & filament current & $80 \mu \mathrm{A}$ \\
\hline & & \multicolumn{2}{|c|}{$1 \mu \mathrm{L}$ of injection volume in splitless } & ion source temperature & $280^{\circ} \mathrm{C}$ \\
\hline & & \multicolumn{2}{|c|}{$300^{\circ} \mathrm{C}$} & collision gas & $\operatorname{argon}(>99.999 \%)$ \\
\hline & & $280^{\circ} \mathrm{C}$ & & collision cell pressure & $2.00 \mathrm{mTorr}$ \\
\hline \multicolumn{4}{|c|}{ GC temperature profile } & collision energy & $5-60 \mathrm{eV}$ \\
\hline Temp $\left({ }^{\circ} \mathrm{C}\right)$ & Rate $\left({ }^{\circ} \mathrm{C} / \mathrm{min}\right)$ & Hold (min) & Total (min) & CID gas & On \\
\hline 45.0 & 0.0 & 1.00 & 1.00 & Collect delay & $4.0 \mathrm{~min}$ \\
\hline 130.0 & 30.0 & 3.00 & 6.83 & Data type & Centroid \\
\hline 180.0 & 12.0 & 0.00 & 11.00 & & \\
\hline 240.0 & 7.0 & 5.00 & 24.57 & & \\
\hline 325.0 & 12.0 & 5.00 & 36.65 & & \\
\hline
\end{tabular}

* The compound confirmation criteria include absolute ion ratio, Quan Ion Pts qualifier integration. Identification of compounds was performed by comparing the GC retention times, background-corrected characteristic spectral masses with those of authentic standards and the set qualitative ion. Quantification of compounds was performed by the set quantitative ion and measurement of peak area of which the value of signal to noise was above 3 and confirmed by GC/EI MRM analysis. But beyond that, the mass spectrometer was coupled with the GC such that the end of the capillary column terminates within $1 \mathrm{~mm}$ of the ion source but did not intercept the electron or ion beams. 
Table S5. Analytical performance of the multi classes of SVOCs.

\begin{tabular}{|c|c|c|c|c|c|c|c|c|c|c|c|c|c|c|c|}
\hline \multirow{2}{*}{ Compounds } & \multirow{2}{*}{$\begin{array}{l}\text { Matrix } \\
\text { effect }(\%)\end{array}$} & \multicolumn{3}{|c|}{ Absolute recovery $(\%)$} & \multicolumn{3}{|c|}{ Relative recovery (\%) } & \multicolumn{3}{|c|}{ Intraday RSDs (\%) } & \multicolumn{3}{|c|}{ Interday RSDs (\%) } & \multirow{2}{*}{$\begin{array}{l}\text { LOD } \\
\left(\mu \mathrm{g} \mathrm{L}^{-1}\right)\end{array}$} & \multirow{2}{*}{$\begin{array}{l}\text { LOQ } \\
\left(\mu \mathrm{g} \mathrm{L}^{-1}\right)\end{array}$} \\
\hline & & $0.2 \mathrm{ng}$ & $2 \mathrm{ng}$ & $20 \mathrm{ng}$ & $0.2 \mathrm{ng}$ & $2 \mathrm{ng}$ & $20 \mathrm{ng}$ & $0.2 \mathrm{ng}$ & $2 \mathrm{ng}$ & $20 \mathrm{ng}$ & $0.2 \mathrm{ng}$ & $2 \mathrm{ng}$ & $20 \mathrm{ng}$ & & \\
\hline Naphthalene & 76.02 & 65.45 & 72.78 & 80.52 & 82.33 & 88.61 & 86.15 & 1.16 & 3.22 & 4.24 & 12.76 & 15.32 & 12.06 & 0.05 & 0.17 \\
\hline Acenaphthylene & 95.47 & 80.03 & 80.33 & 84.04 & 85.61 & 89.34 & 93.74 & 5.86 & 4.82 & 7.54 & 10.86 & 12.63 & 12.84 & 0.11 & 0.36 \\
\hline Acenaphthene & 105.66 & 82.02 & 85.53 & 87.29 & 78.5 & 89.74 & 104.47 & 12.77 & 6.79 & 2.27 & 11.83 & 20.61 & 15.76 & 0.07 & 0.24 \\
\hline Fluorene & 112.45 & 72.66 & 80.46 & 83.11 & 81.53 & 83.11 & 97.28 & 7.42 & 7.47 & 3.08 & 18.48 & 16.25 & 15.27 & 0.15 & 0.50 \\
\hline Phenanthrene & 98.01 & 75.42 & 81.74 & 89.52 & 83.42 & 88.33 & 104.27 & 4.56 & 5.65 & 1.05 & 18.38 & 14.05 & 12.85 & 0.13 & 0.43 \\
\hline Anthracene & 90.59 & 67.43 & 77.64 & 85.93 & 79.29 & 81.32 & 96.41 & 10.79 & 8.54 & 7.51 & 12.01 & 15.88 & 10.72 & 0.13 & 0.44 \\
\hline Fluoranthene & 94.39 & 72.58 & 83.7 & 80.61 & 83.97 & 96.15 & 94.75 & 11.64 & 5.05 & 9.83 & 17.52 & 14.17 & 14.77 & 0.15 & 0.49 \\
\hline Pyrene & 101.21 & 68.74 & 75.53 & 83.82 & 82.57 & 88.45 & 100.76 & 6.06 & 4.24 & 5.44 & 13.19 & 6.98 & 6.335 & 0.16 & 0.54 \\
\hline Benzo(a)anthracene & 104.81 & 79.91 & 85.32 & 83.47 & 111.58 & 99.63 & 109.44 & 8.95 & 3.64 & 1.43 & 17.16 & 14.32 & 14.53 & 0.13 & 0.42 \\
\hline Chrysene & 121.44 & 71.75 & 78.36 & 86.57 & 88.51 & 100.01 & 103.42 & 6.27 & 9.4 & 3.62 & 10.61 & 12.92 & 13.55 & 0.25 & 0.83 \\
\hline Benzo(b)fluoranthene & 103.88 & 77.89 & 71.85 & 85.77 & 87.51 & 88.11 & 93.64 & 6.33 & 8.25 & 2.72 & 18.52 & 12.74 & 11.90 & 0.24 & 0.80 \\
\hline Benzo(k)fluoranthene & 96.32 & 84.3 & 77.38 & 86.21 & 89.46 & 108 & 103.23 & 13.9 & 6.69 & 8.32 & 5.30 & 8.35 & 7.965 & 0.21 & 0.70 \\
\hline Benzo(a)pyrene & 85.68 & 71.79 & 76.66 & 84.87 & 71.09 & 85.59 & 89.87 & 8.27 & 3.02 & 6.93 & 18.29 & 15.1 & 13.1 & 0.31 & 1.04 \\
\hline Indeno(1,2,3-cd)pyrene & 120.34 & 78.96 & 73.23 & 81.37 & 77.35 & 87.41 & 99.5 & 9.92 & 8.8 & 6.6 & 15.23 & 10.87 & 14.76 & 0.33 & 1.09 \\
\hline Dibenz(a,h)anthracene & 108.93 & 86.13 & 74.71 & 90.39 & 84.07 & 105.53 & 102.37 & 7.23 & 6.92 & 6.2 & 10.53 & 11.58 & 16.63 & 0.21 & 0.69 \\
\hline Benzo(g,h,i)perylene & 120.07 & 74.05 & 79.89 & 73.63 & 89.97 & 93.42 & 94.89 & 14.51 & 16.04 & 8.58 & 19.83 & 15.09 & 14.95 & 0.27 & 0.91 \\
\hline DMP & 75.81 & 79.51 & 88.75 & 91.93 & 85.33 & 82.63 & 92.67 & 5.33 & 6.42 & 5.98 & 17.29 & 9.33 & 8.06 & 0.05 & 0.18 \\
\hline DEP & 89.98 & 79.75 & 79.3 & 89.85 & 87.35 & 94.46 & 93.75 & 9.86 & 10.35 & 9.98 & 20.26 & 10.03 & 7.22 & 0.03 & 0.09 \\
\hline DiBP & 102.31 & 74.61 & 87.52 & 88.5 & 88.82 & 106.69 & 104.59 & 7.52 & 4.36 & 2.28 & 8.51 & 7.76 & 10.37 & 0.01 & 0.04 \\
\hline DnBP & 108.55 & 73.08 & 80.4 & 88.51 & 94.4 & 100.03 & 104.57 & 8.44 & 11.82 & 7.09 & 20.06 & 14.06 & 13.31 & 0.03 & 0.10 \\
\hline BBP & 104.94 & 70.84 & 81.43 & 85.65 & 87.28 & 105.52 & 114.04 & 11.86 & 5.95 & 2.3 & 7.46 & 12.31 & 4.46 & 0.09 & 0.30 \\
\hline DEHP & 113.11 & 79.68 & 71.99 & 87.16 & 101.98 & 98.14 & 102.99 & 4.04 & 8.21 & 0.6 & 11.16 & 3.65 & 3.73 & 0.02 & 0.08 \\
\hline DNOP & 90.23 & 76.88 & 85.19 & 95.81 & 88.71 & 93.75 & 90.35 & 7.07 & 0.98 & 2.14 & 18.99 & 13.95 & 14.67 & 0.02 & 0.08 \\
\hline
\end{tabular}




\begin{tabular}{|c|c|c|c|c|c|c|c|c|c|c|c|c|c|c|c|}
\hline PCB-28 & 119.05 & 73.94 & 86.04 & 87.49 & 82.18 & 94.24 & 90.48 & 3.98 & 3.84 & 0.72 & 7.65 & 8.2 & 4.05 & 0.06 & 0.18 \\
\hline PCB-52 & 73.11 & 81 & 82.57 & 91.02 & 85.04 & 80.4 & 88.96 & 6.32 & 7.3 & 4.73 & 7.51 & 7.1 & 5.34 & 0.02 & 0.08 \\
\hline PCB-101 & 115.78 & 76.29 & 79.07 & 84.05 & 72.47 & 80.46 & 93.29 & 7.07 & 6.53 & 7.3 & 12.17 & 6.41 & 7.92 & $<0.01$ & $<0.01$ \\
\hline PCB-118 & 81.43 & 75.37 & 80.35 & 83.91 & 82.27 & 84.81 & 87.98 & 0.59 & 7.41 & 6.78 & 11.98 & 8.21 & 7.65 & 0.04 & 0.13 \\
\hline PCB-138 & 104.31 & 75.52 & 78.14 & 83.19 & 80.25 & 105.02 & 97.18 & 1.03 & 7.23 & 6.57 & 8.97 & 4.55 & 10.41 & $<0.01$ & $<0.01$ \\
\hline PCB-153 & 97.65 & 74.53 & 81.88 & 84.55 & 80.63 & 94.84 & 97.59 & 6.24 & 3.62 & 6.66 & 13.51 & 9.54 & 8.54 & 0.02 & 0.05 \\
\hline PCB-180 & 85.9 & 74.8 & 78.61 & 83.48 & 86.24 & 85.69 & 94.42 & 9.63 & 8.66 & 6.67 & 10.02 & 10.48 & 10.78 & 0.03 & 0.10 \\
\hline PBDE-28 & 86.51 & 76.05 & 77.85 & 92.94 & 70.05 & 81.32 & 97.81 & 7.76 & 4.59 & 5.47 & 7.66 & 10.39 & 4.65 & 0.03 & 0.11 \\
\hline PBDE-47 & 108.37 & 67.66 & 74.63 & 89.17 & 68.84 & 79.34 & 94.54 & 5.02 & 6.81 & 6.37 & 5.16 & 10.55 & 6.77 & 0.03 & 0.10 \\
\hline PBDE-100 & 96.97 & 74.14 & 85.63 & 84.15 & 72.12 & 85.77 & 89.29 & 7.96 & 5.06 & 6.36 & 20.35 & 9.98 & 14.27 & 0.07 & 0.25 \\
\hline PBDE-99 & 90.41 & 76.88 & 89.86 & 97.09 & 84.3 & 83.77 & 90.05 & 8.58 & 6.06 & 9.11 & 15.34 & 11.96 & 13.92 & 0.02 & 0.06 \\
\hline PBDE-153 & 96.08 & 69.66 & 76.71 & 84.71 & 91.86 & 95.2 & 92.74 & 7.55 & 5.78 & 6.44 & 12.88 & 11.41 & 9.41 & 0.09 & 0.30 \\
\hline Dichlorvos & 118.08 & 80.68 & 82.1 & 90.22 & 78.46 & 88.08 & 93.79 & 4.97 & 4.28 & 3.39 & 17.49 & 10.68 & 8.21 & 0.06 & 0.19 \\
\hline Mevinphos & 97.46 & 79.44 & 80.37 & 90.03 & 100.38 & 101.02 & 100.21 & 5.78 & 9.91 & 4.98 & 14.77 & 5.65 & 13.08 & 0.12 & 0.39 \\
\hline Propham & 117.31 & 72.42 & 86.89 & 94.05 & 82.61 & 92.46 & 90.42 & 9.1 & 6.86 & 11.86 & 13.84 & 9.83 & 11.52 & 0.07 & 0.22 \\
\hline Ethoprophos & 91.36 & 77.63 & 87.39 & 95.22 & 75.88 & 86.91 & 92.5 & 11.8 & 4.26 & 7.36 & 18.29 & 10.32 & 8.89 & 0.04 & 0.14 \\
\hline Trifluralin & 109.99 & 78.34 & 85.11 & 84.13 & 91.98 & 89.52 & 97.66 & 7.54 & 8.4 & 6.78 & 12.09 & 15.14 & 6.43 & 0.10 & 0.32 \\
\hline Phorate & 90.74 & 79.01 & 84.43 & 83.73 & 76.36 & 81.65 & 90.95 & 3.63 & 5.53 & 3.78 & 15.06 & 12.41 & 8.51 & 0.08 & 0.26 \\
\hline$\alpha-\mathrm{BHC}$ & 81.37 & 80.16 & 83.81 & 86.59 & 97.6 & 83.4 & 111.01 & 7.57 & 9.6 & 1.1 & 15.31 & 14.61 & 6.11 & 0.03 & 0.09 \\
\hline Hexachlorobenzene & 107.25 & 78.08 & 85.41 & 89.69 & 79.79 & 85.57 & 99.75 & 7.12 & 7.2 & 8.13 & 19.8 & 19.22 & 19.92 & $<0.01$ & $<0.01$ \\
\hline Atrazine & 114.41 & 76.78 & 75.48 & 82.87 & 81.77 & 101.17 & 103.62 & 7.83 & 9.89 & 7.29 & 18.59 & 10.7 & 6.29 & 0.01 & 0.02 \\
\hline Methiamitron & 106.78 & 75.04 & 81.3 & 82.59 & 75.13 & 90.7 & 95.13 & 4.46 & 7.92 & 5.73 & 19.75 & 8.98 & 6.20 & 0.30 & 0.99 \\
\hline$\beta-\mathrm{BHC}$ & 116.24 & 78.12 & 79.54 & 84.87 & 88.59 & 82.72 & 87.35 & 5.16 & 8.56 & 7.03 & 14.78 & 8.21 & 5.40 & 0.10 & 0.34 \\
\hline Quintozene & 102.33 & 82.58 & 84.78 & 88.81 & 81.83 & 80.91 & 90.7 & 3.86 & 9.21 & 8.42 & 13.34 & 14.27 & 10.77 & $<0.01$ & 0.01 \\
\hline$\gamma$-BHC & 89.08 & 80.27 & 80.71 & 83.47 & 75.54 & 79.03 & 87.84 & 4.36 & 8.1 & 8.58 & 12.54 & 12.77 & 5.79 & 0.07 & 0.24 \\
\hline Propyzamide & 96.32 & 72.52 & 79.14 & 89.91 & 82.98 & 93.13 & 97.32 & 5.09 & 2.2 & 2.3 & 21.43 & 11.03 & 9.91 & 0.33 & 1.11 \\
\hline
\end{tabular}




\begin{tabular}{|c|c|c|c|c|c|c|c|c|c|c|c|c|c|c|c|}
\hline Diazinon & 101.36 & 81.15 & 84.78 & 83.92 & 81.79 & 101.85 & 107.22 & 4.88 & 7.86 & 6.96 & 12.63 & 13.52 & 7.96 & 0.09 & 0.31 \\
\hline Etrimfos & 120.03 & 80.3 & 86.87 & 95.15 & 81.3 & 91.52 & 89.63 & 8.73 & 7.445 & 6.84 & 15.66 & 15.22 & 5.33 & 0.15 & 0.50 \\
\hline$\delta$-BHC & 111.89 & 82.02 & 81.25 & 95.96 & 95.51 & 103.82 & 111.44 & 6.06 & 8.7 & 7.00 & 14.25 & 11.04 & 9.42 & 0.13 & 0.44 \\
\hline Benoxacor & 73.12 & 78.1 & 78.67 & 85.81 & 90.92 & 88.4 & 93.58 & 4.75 & 8.27 & 5.38 & 14.33 & 12.67 & 10.04 & 0.17 & 0.57 \\
\hline Acetochlor & 111.56 & 69.36 & 79.51 & 83.3 & 70.09 & 86.75 & 95.02 & 6.95 & 9.03 & 1.73 & 18.24 & 11.67 & 6.13 & 0.21 & 0.71 \\
\hline Chlorpyrifos-methyl & 80.52 & 78.71 & 79.16 & 82.37 & 88.81 & 95.76 & 104.74 & 5.7 & 8.57 & 8.25 & 11.48 & 8.85 & 5.39 & $<0.01$ & $<0.01$ \\
\hline ParathionMethyl & 88.25 & 69.06 & 82.15 & 87.02 & 86.19 & 89.29 & 92.59 & 13.04 & 5.45 & 8.47 & 11.44 & 13.21 & 8.21 & 0.13 & 0.42 \\
\hline Heptachlor & 73.38 & 79.8 & 79.1 & 83.25 & 87.87 & 89.05 & 92.13 & 5.71 & 8.65 & 7.14 & 10.33 & 10.78 & 6.46 & $<0.01$ & $<0.01$ \\
\hline Ametryn & 92.64 & 78.18 & 78.35 & 85.61 & 105.33 & 105.69 & 108.79 & 7.73 & 9.68 & 7.91 & 13.92 & 9.6 & 6.22 & 0.07 & 0.22 \\
\hline Prometryn & 86.27 & 88.37 & 93.75 & 93.25 & 80.72 & 86.31 & 86.69 & 8.94 & 8.8 & 8.62 & 15.77 & 18.54 & 15.50 & $<0.01$ & 0.01 \\
\hline PirimiphosMethyl & 104.16 & 87.39 & 91.57 & 90.4 & 76.34 & 85.03 & 88.4 & 13.08 & 5.9 & 7.49 & 12.04 & 20.03 & 19.43 & $<0.01$ & $<0.01$ \\
\hline Fenitrothion & 100.96 & 88.47 & 87.54 & 91 & 77.75 & 87.47 & 87.19 & 3.99 & 8.11 & 6.29 & 17.67 & 19.83 & 12.98 & $<0.01$ & $<0.01$ \\
\hline Malathion & 109.93 & 82.71 & 88.49 & 87.93 & 82.06 & 88.62 & 92.49 & 6.87 & 9.93 & 5.88 & 13.82 & 13.61 & 7.63 & 0.25 & 0.85 \\
\hline Metolachlor & 90.2 & 78.57 & 80.6 & 90.69 & 82.25 & 94.92 & 94.39 & 3.71 & 9.37 & 6.77 & 16.75 & 10.78 & 6.55 & 0.07 & 0.23 \\
\hline Aldrin & 116.2 & 81.99 & 88.56 & 93.93 & 77.87 & 84.38 & 93.17 & 11.44 & 7.65 & 7.35 & 16.7 & 10.56 & 10.41 & $<0.01$ & $<0.01$ \\
\hline Cyanazine & 71.33 & 71.64 & 76.15 & 81.59 & 80.27 & 88.12 & 93.04 & 8.65 & 6.165 & 6.14 & 11.08 & 12.1 & 12.71 & $<0.01$ & $<0.01$ \\
\hline PirimiphosEthyl & 110.47 & 73.36 & 83.03 & 87.56 & 86.76 & 118.12 & 120.3 & 6.55 & 9.92 & 6.94 & 17.67 & 10.49 & 6.31 & $<0.01$ & $<0.01$ \\
\hline Isofenphos & 72.98 & 74.04 & 80.98 & 85.69 & 90.73 & 99.22 & 100.44 & 5.26 & 9.51 & 7.58 & 12.19 & 9.66 & 6.87 & 0.03 & 0.10 \\
\hline Chlorfenvinphos & 89.93 & 72.04 & 89.29 & 91.66 & 80.12 & 97.68 & 94.72 & 4.38 & 4.56 & 1.13 & 11.94 & 7.8 & 7.29 & 0.03 & 0.11 \\
\hline Phenthoate & 101.32 & 83.24 & 80.23 & 86.77 & 82.87 & 89.16 & 93.23 & 6.44 & 0.6 & 2.33 & 2.42 & 14.75 & 12.67 & $<0.01$ & $<0.01$ \\
\hline Quinalphos & 103.78 & 82.54 & 85.09 & 93.51 & 89.11 & 90.12 & 96.67 & 4.74 & 1.27 & 2.52 & 6.43 & 11.25 & 5.3 & 0.30 & 1.00 \\
\hline Methidathion & 75.37 & 82.27 & 82.33 & 89.4 & 88.82 & 115.97 & 114.17 & 4.46 & 8.84 & 5.65 & 10.27 & 13.11 & 5.96 & 0.03 & 0.09 \\
\hline$o, p^{\prime}-\mathrm{DDE}$ & 113.1 & 82.64 & 81.36 & 84.4 & 83.85 & 106.52 & 102.63 & 6.35 & 8.88 & 6.91 & 12.18 & 6.34 & 8.69 & 0.02 & 0.05 \\
\hline Tetrachlorvinphos & 100.16 & 75.79 & 80.81 & 96.64 & 75.62 & 88.67 & 87.38 & 6.08 & 9.39 & 9.18 & 15.43 & 12.62 & 8.85 & $<0.01$ & $<0.01$ \\
\hline Paclobutrazol & 108.72 & 80.44 & 83.16 & 91.27 & 80.26 & 111.93 & 101.64 & 6.16 & 7.36 & 7.23 & 11.19 & 11.34 & 12.94 & $<0.01$ & $<0.01$ \\
\hline Butachlor & 93.36 & 86.45 & 87.23 & 87.17 & 87.45 & 95.12 & 95.58 & 5.81 & 8.95 & 7 & 13.19 & 10.14 & 4.23 & 0.16 & 0.54 \\
\hline
\end{tabular}




\begin{tabular}{|c|c|c|c|c|c|c|c|c|c|c|c|c|c|c|c|}
\hline$\alpha$-Endosulfan & 112.49 & 79.14 & 78.78 & 83.92 & 81.84 & 108.39 & 104.33 & 20.74 & 16.25 & 10.85 & 10.28 & 9.27 & 3.61 & $<0.01$ & 0.01 \\
\hline Fenamiphos & 105.6 & 78.71 & 83.44 & 90.27 & 73.11 & 103.08 & 100.2 & 2.78 & 3.625 & 0.85 & 17.27 & 13.13 & 15.32 & 0.27 & 0.91 \\
\hline Napropamide & 97.71 & 86.91 & 84.03 & 85.88 & 89.84 & 123.83 & 111.84 & 6.48 & 4.775 & 1.09 & 13.74 & 16.22 & 13.74 & 0.40 & 1.33 \\
\hline Profenofos & 118.74 & 76.61 & 83.04 & 94.92 & 73.97 & 79.66 & 84.51 & 6.12 & 5.11 & 5.44 & 15.02 & 8.79 & 6.88 & 0.41 & 1.38 \\
\hline$p, p^{\prime}-\mathrm{DDE}$ & 105.16 & 81.34 & 81.63 & 84.38 & 73.76 & 87.62 & 89.74 & 6.17 & 4.66 & 7.6 & 11.46 & 6.05 & 8.8 & 0.02 & 0.07 \\
\hline Oxadiazon & 98.09 & 81.75 & 83.82 & 86.14 & 80.3 & 89.34 & 85.15 & 4.99 & 5.12 & 7.26 & 15.39 & 8.71 & 4.69 & $<0.01$ & $<0.01$ \\
\hline Dieldrin & 93.96 & 83.65 & 77.54 & 85.23 & 93.38 & 97.04 & 97.57 & 5.88 & 4.21 & 8.45 & 16.33 & 5.58 & 4.58 & $<0.01$ & $<0.01$ \\
\hline$o, p^{\prime}-\mathrm{DDD}$ & 72.84 & 82.33 & 82.6 & 86.41 & 79.15 & 88.79 & 86.59 & 5.98 & 4.83 & 8.55 & 15.73 & 6.81 & 5.69 & 0.03 & 0.09 \\
\hline Oxyfluorfen & 106.31 & 83.53 & 83.58 & 86.62 & 97.58 & 109.99 & 103.35 & 3.96 & 5.03 & 5.85 & 18.86 & 7.01 & 5.97 & $<0.01$ & 0.01 \\
\hline Nitrofen & 101.58 & 87.64 & 86.03 & 96.78 & 70.03 & 87.38 & 93.56 & 6.76 & 5.06 & 9.80 & 15.58 & 7.89 & 4.67 & $<0.01$ & 0.01 \\
\hline Endrin & 83.1 & 80.55 & 82.88 & 85.77 & 82.61 & 92.4 & 90.5 & 7.27 & 4.44 & 7.81 & 8.97 & 6.57 & 4.2 & 0.20 & 0.67 \\
\hline Fluazifop-butyl & 81.12 & 83.69 & 81.17 & 85.27 & 68.23 & 92.08 & 90.81 & 6.09 & 5.22 & 9.58 & 13.79 & 8.51 & 4.34 & 0.14 & 0.48 \\
\hline$\beta$-Endosulfan & 75.47 & 81.4 & 83.54 & 86.57 & 76.13 & 85.93 & 90.04 & 20.91 & 17.66 & 14.70 & 5.53 & 6.76 & 4.02 & 0.07 & 0.22 \\
\hline Ethion & 99.93 & 80.42 & 81.57 & 82.88 & 75.74 & 100.41 & 104.05 & 10.01 & 4.93 & 8.54 & 6.21 & 11.89 & 5.53 & 0.11 & 0.38 \\
\hline$p, p^{\prime}-\mathrm{DDD}$ & 97.64 & 93.41 & 83.05 & 85.67 & 72.23 & 89.14 & 96.51 & 6.47 & 4.61 & 7.00 & 10.57 & 7.59 & 5.21 & 0.02 & 0.08 \\
\hline$o, p^{\prime}-\mathrm{DDT}$ & 99.58 & 78.54 & 84.01 & 84.73 & 67.24 & 90.7 & 91.4 & 6.58 & 4.71 & 9.29 & 19.24 & 7.34 & 8.82 & 0.04 & 0.12 \\
\hline$p, p^{\prime}-\mathrm{DDT}$ & 92.74 & 87.46 & 85.83 & 85.09 & 78.42 & 100.05 & 101.96 & 5.46 & 4.25 & 5.35 & 14.3 & 10.78 & 7.76 & 0.09 & 0.29 \\
\hline Pyridaphenthion & 119.33 & 88.66 & 83.11 & 94.71 & 90.1 & 87.4 & 84.76 & 3.11 & 5.915 & 5.35 & 11.49 & 12.78 & 7.05 & 0.16 & 0.52 \\
\hline Bifenthrin & 110.75 & 88.68 & 86.81 & 91.1 & 82.13 & 102.33 & 116.79 & 5.63 & 4.78 & 4.49 & 18.48 & 13.53 & 11.09 & 0.14 & 0.48 \\
\hline Fenpropathrin & 98.81 & 77.3 & 91.51 & 92 & 82.28 & 82.18 & 94.45 & 11.34 & 6.86 & 2.99 & 15.94 & 15.81 & 8.43 & 0.14 & 0.46 \\
\hline Phosalone & 101.4 & 68.33 & 84.94 & 86.58 & 68.19 & 76.63 & 81.57 & 5.71 & 6.33 & 8.46 & 11.38 & 11.61 & 5.83 & 0.12 & 0.41 \\
\hline Delta-Cyhalothrin & 78.02 & 93.51 & 86.96 & 91.22 & 81.84 & 83.44 & 90.63 & 1.53 & 4.26 & 3.55 & 11.74 & 13.11 & 11.09 & 0.13 & 0.42 \\
\hline Permethrin & 89.56 & 69.87 & 85.28 & 91.1 & 94.27 & 95.86 & 90.95 & 6.51 & 1.73 & 3.85 & 12.1 & 11.52 & 9.07 & 0.24 & 0.80 \\
\hline Coumaphos & 104.96 & 78.1 & 82.44 & 83.76 & 73.49 & 80.63 & 93.76 & 4.78 & 6.92 & 7.46 & 10.72 & 6.71 & 7.38 & 0.28 & 0.93 \\
\hline Cyfluthrin & 91.88 & 66.52 & 70.24 & 92.46 & 72.67 & 86.21 & 90.02 & 7.51 & 3.72 & 3.04 & 7.24 & 10.82 & 10.43 & 0.20 & 0.65 \\
\hline Cypermethrin & 75.49 & 77.02 & 88.84 & 90.75 & 67.11 & 85.74 & 89.89 & 6.63 & 10.40 & 6.81 & 15.49 & 15.56 & 15.34 & 0.14 & 0.45 \\
\hline
\end{tabular}




\begin{tabular}{|c|c|c|c|c|c|c|c|c|c|c|c|c|c|c|c|}
\hline Fenvalerate & 103.54 & 75.08 & 86.47 & 87.35 & 89.39 & 109.19 & 106.42 & 8.06 & 2.26 & 3.28 & 13.66 & 13.86 & 10.55 & 0.26 & 0.87 \\
\hline Deltamethrin & 79.28 & 82.76 & 81.28 & 90.57 & 89.18 & 94.7 & 92.18 & 6.22 & 7.09 & 2.52 & 17.36 & 6.77 & 4.48 & 0.16 & 0.54 \\
\hline
\end{tabular}
*LOD lower than $0.01 \mu \mathrm{g} \mathrm{L}{ }^{-1}$ was described as $<0.01 \mu \mathrm{g} \mathrm{L}{ }^{-1}$. 
Table S6. Comparison of the developed method with others reported.

\begin{tabular}{|c|c|c|c|c|c|c|c|c|c|}
\hline Compounds & $\begin{array}{l}\text { Sample } \\
\text { (volume) }\end{array}$ & $\begin{array}{l}\text { Protein } \\
\text { denatured }\end{array}$ & Extraction procedure & Cleanup & $\begin{array}{l}\text { Instrumental } \\
\text { analysis }\end{array}$ & Relative recovery (\%) & RSD (\%) & LOD & Ref. \\
\hline $\begin{array}{l}103 \text { SVOCs } \\
\text { (7 PAEs / } 16 \text { PAHs / } \\
7 \text { PCBs / } 5 \text { PBDEs / } \\
68 \text { pesticides) }\end{array}$ & $0.5 \mathrm{~mL}$ serum & $1 \mathrm{~mL} \mathrm{ACN}$ & $\begin{array}{l}\text { Multistage extraction: } 3 \mathrm{~mL} \\
\text { hexane, } 0.2 \mathrm{~mL} \text { DCM }\end{array}$ & $\begin{array}{l}\text { Florisil }(500 \mathrm{mg}), \text { load: } 0.2 \mathrm{~mL} \text { hexane, } \\
\text { elute: } 2 \mathrm{~mL} \text { hexane/DCM }(8: 2, \mathrm{v} / \mathrm{v}), 2 \mathrm{~mL} \\
\text { hecane/ EtAc }(8: 2, \mathrm{v} / \mathrm{v}) \text { and } 2 \mathrm{~mL} \\
\text { hexane/DCM }(1: 1, \mathrm{v} / \mathrm{v})\end{array}$ & GC-MS/MS & $\begin{array}{l}\text { PAHs: } 71.09-111.58 \\
\text { PAEs: } 82.63-114.04 \\
\text { PCBs: } 72.47-105.02 \\
\text { PBDEs: } 68.84-97.81 \\
\text { Pesticides: } 67.11-123.83\end{array}$ & $0.59-21.43$ &  & This study \\
\hline $\begin{array}{l}26 \text { SVOCs } \\
(15 \text { PCBs / } 6 \text { PBDEs } \\
\text { / } 1 \text { PBB / } 4 \text { OCPs })\end{array}$ & $\sim 2 \mathrm{~g}$ serum & $\begin{array}{l}5 \mathrm{ml} \text { formic } \\
\text { acid:2-propanol } \\
(4: 1, \mathrm{v} / \mathrm{v})\end{array}$ & $\begin{array}{l}\text { Solid-phase extraction: } \\
\text { ASPEC XL4, load: the } \\
\text { diluted sample by water/2- } \\
\text { propanol }(4: 1, \mathrm{v} / \mathrm{v}) \text {, elute: } \\
\text { DCM/MeOH}(7: 3, \mathrm{v} / \mathrm{v})\end{array}$ & $\begin{array}{l}400 \mathrm{mg} / 3 \mathrm{~mL} \text { Oasis } \odot \text { HLB-columns, load: } \\
3.5 \mathrm{ml} \text { n-heptane/DCM }(3: 1, \mathrm{v} / \mathrm{v}) \text {, elute: } \mathrm{n} \text { - } \\
\text { heptane/DCM }(3: 1, \mathrm{v} / \mathrm{v})\end{array}$ & $\begin{array}{l}\text { High resolution } \\
\text { mass } \\
\text { spectrometry(GC- } \\
\text { HRMS) }\end{array}$ & - & $<20$ & $\begin{array}{l}\text { PCBs: } 12.5 \mathrm{pg} / \mathrm{g} \\
\text { PBDEs: } 5 \mathrm{pg} / \mathrm{g} \\
\text { OCPs: } 25 \mathrm{pg} / \mathrm{g}\end{array}$ & 3 \\
\hline $\begin{array}{l}36 \text { SVOCs } \\
\text { (26 PCBs / } 3 \text { PBDEs } \\
\text { / } 7 \text { OCPs) }\end{array}$ & $2 \mathrm{~mL}$ serum & $\begin{array}{l}2 \mathrm{~mL} \text { formic } \\
\text { acid and } 100 \mu \mathrm{L} \\
\text { ACN }\end{array}$ & $\begin{array}{l}\text { Solid-phase extraction: HLB, } \\
\text { load: the fortified serum } \\
\text { mixture, elute: } 5 \mathrm{~mL} \text { DCM }\end{array}$ & $\begin{array}{l}2 \mathrm{~mL} \text { hexane were used to redissolve the } \\
\text { compounds and } 1 \mathrm{~mL} \mathrm{H} 2 \mathrm{SO} 4 \text { was added } \\
\text { A silica cartridge (3cc, } 500 \mathrm{mg} \text {. Waters) with } \\
44 \% \text { acidified silica and anhydrous } \mathrm{Na}_{2} \mathrm{SO} 4 \text {, } \\
\text { load: hexane, elute: } 6 \mathrm{~mL} \text { DCM }\end{array}$ & $\begin{array}{l}\text { GC- } \mu \text { ECD, GC- } \\
\text { 5975C MSD, GC- } \\
\text { 5977A MSD }\end{array}$ & $\begin{array}{l}\text { PCBs: } 79.3-104.1 \\
\text { PBDEs: } 88.6-102.1 \\
\text { OCPs: } 78.4-116.8\end{array}$ & - & $\begin{array}{l}\text { PCBs: } 0.1-0.9 \mathrm{ng} / \mathrm{g} \\
\text { PBDEs: } 0.02-1 \mathrm{ng} / \mathrm{g} \\
\text { OCPs: } 0.06-0.2 \mathrm{ng} / \mathrm{g}\end{array}$ & 4 \\
\hline $\begin{array}{l}57 \text { SVOCs } \\
\text { (31 PCBs / } 15 \\
\text { PBDEs / } 11 \text { OCPs) }\end{array}$ & $3 \mathrm{~g}$ plasma & $\mathrm{MeOH}$ & $\begin{array}{l}\text { Liquid-liquid extraction: } \\
\text { hexane-DCM-acetone } \\
(1: 1: 0.6)\end{array}$ & silica gel columns & GC-MS (ion trap) & 57 SVOCs: $67-122$ & $21-25$ & $\begin{array}{l}\text { PCBs: } 0.2-2 \mathrm{ng} / \mathrm{g} \\
\text { PBDEs: } 0.4-20 \mathrm{ng} / \mathrm{g} \\
\text { OCPs: } 0.2-2 \mathrm{ng} / \mathrm{g}\end{array}$ & 5 \\
\hline $\begin{array}{l}85 \text { SVOCs } \\
\text { (38 PCBs / } 23 \\
\text { PBDEs / } 24 \text { OCPs) }\end{array}$ & $200 \mu \mathrm{L}$ serum & - & $\begin{array}{l}\text { Liquid-liquid extraction: } 1 \\
\mathrm{~mL} \text { of EtAc/hexane/acetone } \\
(1: 1: 2, \mathrm{v} / \mathrm{v} / \mathrm{v}) 200 \mathrm{mg} \text { of } \\
\mathrm{MgSO}_{4}\end{array}$ & $\begin{array}{l}\text { QuEChERS cleanup, purify: } 200 \mathrm{mg} \text { of } \\
\mathrm{MgSO}_{4}, 50 \mathrm{mg} \text { of } \mathrm{NaCl} \text { and } 100 \mathrm{mg} \text { PSA, } \\
\text { extract: } 1 \mathrm{~mL} \text { of EtAc/hexane/acetone (1:1:2, } \\
\mathrm{v} / \mathrm{v} / \mathrm{v}) \text {, purify: } 100 \mathrm{mg} \text { PSA }\end{array}$ & $\begin{array}{l}\text { GC-EI-MS/MS } \\
\text { GC-APCI- } \\
\text { MS/MS }\end{array}$ & $\begin{array}{l}\text { PCBs: } 81.2-113.1 \\
\text { PBDEs: } 85.8-112.2 \\
\text { OCPs: } 55.2-113.9\end{array}$ & $0.8-34.3$ & $\begin{array}{l}\text { PCBs: } 0.5-10 \mathrm{ng} / \mathrm{L} \\
\text { PBDEs: } 2-20 \mathrm{ng} / \mathrm{L} \\
\text { OCPs: } 2-40 \mathrm{ng} / \mathrm{L}\end{array}$ & 6 \\
\hline $\begin{array}{l}103 \text { SVOCs } \\
(16 \text { PAHs / } 56 \text { PCBs } \\
\text { / } 11 \text { PBDEs / } 20 \\
\text { OCPs) }\end{array}$ & $0.8 \mathrm{~mL}$ serum & $1 \mathrm{~mL} \mathrm{MeOH}$ & $\begin{array}{l}\text { Liquid-liquid extraction: } 3 \\
\mathrm{~mL} \text { hexane/methyl tert-butyl } \\
\text { ether }(1: 1, \mathrm{v} / \mathrm{v})\end{array}$ & $\begin{array}{l}\text { QuEChERS cleanup, load: } 1 \mathrm{mLACN} \text {, } \\
\text { purify: MgSO4 ( } 30 \mathrm{mg}), \mathrm{PSA}(60 \mathrm{mg}) \text {, and } \\
\text { C18 }(60 \mathrm{mg}) \text {, extract: } 3 \mathrm{~mL} \text { hexane/methyl } \\
\text { tert-butyl ether }(1: 1, \mathrm{v} / \mathrm{v}), \mathrm{ACN} ; \\
\text { GPC cleanup, elute: hexane/DCM }(1: 1, \mathrm{v} / \mathrm{v}) \text {; } \\
\text { AlO/SiG cleanup, elute: } 20 \mathrm{~mL} \\
\text { hexane/DCM }(1: 1, \mathrm{v} / \mathrm{v})\end{array}$ & $\begin{array}{l}\text { GC-MS/MS } \\
\text { GC-MS }\end{array}$ & 103 SVOCs: $64-120$ & $0.3-16.4$ & - & 7 \\
\hline
\end{tabular}


Table S7. Concentrations of SVOCs in serum samples $\left(\mu \mathrm{g} \mathrm{L}^{-1}, \mathrm{n}=99\right)$.

\begin{tabular}{|c|c|c|c|c|c|}
\hline Compounds & NO. $(\%)$ & Mean & $\mathrm{SD}$ & Median & Range \\
\hline Naphthalene & $99,(100)$ & 2.41 & 1.18 & 2.08 & $0.56-6.55$ \\
\hline Acenaphthylene & $63,(64)$ & 0.47 & 0.38 & 0.46 & $<$ LOD-1.6 \\
\hline Acenaphthene & $76,(77)$ & 0.4 & 0.29 & 0.38 & $<$ LOD-1.16 \\
\hline Fluorene & $99,(100)$ & 1.7 & 0.41 & 1.62 & $0.96-2.65$ \\
\hline Phenanthrene & $99,(100)$ & 0.97 & 0.34 & 0.87 & $0.5-1.81$ \\
\hline Anthracene & $99,(100)$ & 2 & 1.23 & 1.81 & $1.16-9.19$ \\
\hline Fluoranthene & $99,(100)$ & 10.74 & 6.93 & 9.74 & $3.08-36.99$ \\
\hline Pyrene & $76,(77)$ & 0.94 & 0.56 & 1 & $<$ LOD-2.04 \\
\hline Benzo(a)anthracene & $99,(100)$ & 38.61 & 16.93 & 44.15 & $11.69-67.91$ \\
\hline Chrysene & $99,(100)$ & 79.72 & 40.3 & 87.34 & $16.6-156.68$ \\
\hline Benzo(b)fluoranthene & $99,(100)$ & 5.06 & 2.87 & 5.74 & $0.64-11.05$ \\
\hline Benzo(k)fluoranthene & $99,(100)$ & 13.26 & 6.75 & 15.52 & $3.59-25.78$ \\
\hline Benzo(a)pyrene & $89,(90)$ & 3.46 & 2.15 & 3.88 & $<$ LOD-8.27 \\
\hline Indeno(1,2,3-cd)pyrene & $99,(100)$ & 47.22 & 18.23 & 44.04 & $21.82-102.11$ \\
\hline $\operatorname{Dibenz}(\mathrm{a}, \mathrm{h})$ anthracene & $99,(100)$ & 35.35 & 12.35 & 33.59 & $14.76-65.57$ \\
\hline Benzo(g,h,i)perylene & $99,(100)$ & 8.17 & 2.79 & 8.34 & $4.35-14.83$ \\
\hline DMP & $99,(100)$ & 2.88 & 2.8 & 1.84 & $0.76-16.04$ \\
\hline DEP & $99,(100)$ & 18.61 & 4.62 & 19.05 & $8.71-27.22$ \\
\hline DiBP & $99,(100)$ & 7.54 & 6.52 & 5.2 & $0.88-31.06$ \\
\hline DnBP & $99,(100)$ & 43.77 & 21.88 & 40.7 & $19.37-144.27$ \\
\hline BBP & $99,(100)$ & 2.33 & 0.56 & 2.28 & $1.56-4.69$ \\
\hline DEHP & $99,(100)$ & 42.34 & 30.12 & 34.14 & $11.73-137.84$ \\
\hline DNOP & $69,(70)$ & 1 & 0.65 & 1.06 & $<$ LOD-2.94 \\
\hline PCB-28 & $99,(100)$ & 0.23 & 0.03 & 0.21 & $0.21-0.38$ \\
\hline PCB-52 & $13,(13)$ & 0.03 & 0.03 & $<\mathrm{LOD}$ & $<$ LOD -0.13 \\
\hline PCB-101 & $99,(100)$ & 0.16 & 0.04 & 0.15 & $0.12-0.26$ \\
\hline PCB-118 & $99,(100)$ & 0.83 & 0.11 & 0.8 & $0.69-1.07$ \\
\hline PCB-138 & $99,(100)$ & 0.66 & 0.06 & 0.65 & $0.56-0.84$ \\
\hline PCB-153 & $99,(100)$ & 1.9 & 0.64 & 1.87 & $0.93-3.16$ \\
\hline PCB-180 & $99,(100)$ & 0.52 & 0.03 & 0.51 & $0.5-0.64$ \\
\hline PBDE-28 & $0,(0)$ & $<\mathrm{LOD}$ & 0 & $<\mathrm{LOD}$ & $<\mathrm{LOD}$ \\
\hline PBDE-47 & $0,(0)$ & $<\mathrm{LOD}$ & 0 & $<\mathrm{LOD}$ & $<\mathrm{LOD}$ \\
\hline PBDE-100 & $0,(0)$ & $<\mathrm{LOD}$ & 0 & $<\mathrm{LOD}$ & $<\mathrm{LOD}$ \\
\hline PBDE-99 & $0,(0)$ & $<\mathrm{LOD}$ & 0 & $<\mathrm{LOD}$ & $<\mathrm{LOD}$ \\
\hline PBDE-153 & $0,(0)$ & $<\mathrm{LOD}$ & 0 & $<\mathrm{LOD}$ & $<\mathrm{LOD}$ \\
\hline Dichlorvos & $38,(38)$ & 0.12 & 0.11 & $<\mathrm{LOD}$ & $<$ LOD-0.35 \\
\hline Mevinphos & $63,(64)$ & 0.41 & 0.26 & 0.52 & $<$ LOD- 0.78 \\
\hline Propham & $94,(95)$ & 0.27 & 0.19 & 0.23 & $<$ LOD -0.76 \\
\hline Ethoprophos & $99,(100)$ & 0.68 & 0.05 & 0.68 & $0.59-0.79$ \\
\hline Trifluralin & $99,(100)$ & 0.24 & 0.1 & 0.24 & $0.1-0.48$ \\
\hline Phorate & $94,(95)$ & 0.15 & 0.06 & 0.15 & $<$ LOD -0.28 \\
\hline$\alpha-\mathrm{BHC}$ & $99,(100)$ & 0.33 & 0.16 & 0.31 & $0.11-0.86$ \\
\hline
\end{tabular}




\begin{tabular}{|c|c|c|c|c|c|}
\hline Hexachlorobenzene & $99,(100)$ & 1.43 & 0.79 & 1.26 & $0.45-4.94$ \\
\hline Atrazine & $99,(100)$ & 0.55 & 0.3 & 0.45 & $0.12-1.38$ \\
\hline Methiamitron & $0,(0)$ & $<\mathrm{LOD}$ & 0 & $<\mathrm{LOD}$ & $<\mathrm{LOD}$ \\
\hline$\beta-\mathrm{BHC}$ & $74,(75)$ & 0.94 & 0.85 & 0.82 & $<$ LOD-3.97 \\
\hline Quintozene & $99,(100)$ & 0.53 & 0.38 & 0.38 & $0.22-1.75$ \\
\hline$\gamma$-BHC & $99,(100)$ & 1 & 0.36 & 0.98 & $0.35-1.88$ \\
\hline Propyzamide & $0,(0)$ & $<\mathrm{LOD}$ & 0 & $<\mathrm{LOD}$ & $<\mathrm{LOD}$ \\
\hline Diazinon & $91,(92)$ & 0.83 & 0.5 & 0.75 & $<$ LOD-2.11 \\
\hline Etrimfos & $0,(0)$ & $<\mathrm{LOD}$ & 0 & $<\mathrm{LOD}$ & $<\mathrm{LOD}$ \\
\hline$\delta$-BHC & $99,(100)$ & 0.16 & 0.01 & 0.16 & $0.14-0.19$ \\
\hline Benoxacor & $0,(0)$ & $<\mathrm{LOD}$ & 0 & $<\mathrm{LOD}$ & $<\mathrm{LOD}$ \\
\hline Acetochlor & $0,(0)$ & $<\mathrm{LOD}$ & 0 & $<\mathrm{LOD}$ & $<\mathrm{LOD}$ \\
\hline Chlorpyrifos-methyl & $99,(100)$ & 0.31 & 0.09 & 0.26 & $0.26-0.7$ \\
\hline ParathionMethyl & $99,(100)$ & 0.27 & 0.07 & 0.27 & $0.16-0.41$ \\
\hline Heptachlor & $99,(100)$ & 0.39 & 0.07 & 0.35 & $0.35-0.67$ \\
\hline Ametryn & $99,(100)$ & 0.76 & 0.36 & 0.82 & $0.16-1.48$ \\
\hline Prometryn & $99,(100)$ & 0.38 & 0.25 & 0.34 & $0.03-1$ \\
\hline PirimiphosMethyl & $99,(100)$ & 0.87 & 0.41 & 0.77 & $0.35-2.17$ \\
\hline Fenitrothion & $99,(100)$ & 0.67 & 0.39 & 0.61 & $0.09-1.46$ \\
\hline Malathion & $99,(100)$ & 1.04 & 0.35 & 1.02 & $0.43-1.76$ \\
\hline Metolachlor & $71,(72)$ & 0.11 & 0.06 & 0.11 & $<$ LOD -0.28 \\
\hline Aldrin & $99,(100)$ & 0.45 & 0.3 & 0.35 & $0.04-1.06$ \\
\hline Cyanazine & $99,(100)$ & 0.67 & 0.39 & 0.61 & $0.09-1.46$ \\
\hline PirimiphosEthyl & $99,(100)$ & 1.04 & 0.35 & 1.02 & $0.43-1.76$ \\
\hline Isofenphos & $99,(100)$ & 0.12 & 0.06 & 0.11 & $0.04-0.28$ \\
\hline Chlorfenvinphos & $61,(62)$ & 0.05 & 0.03 & 0.03 & $<$ LOD -0.11 \\
\hline Phenthoate & $99,(100)$ & 0.17 & 0.07 & 0.13 & $0.12-0.4$ \\
\hline Quinalphos & $36,(36)$ & 0.29 & 0.14 & $<\mathrm{LOD}$ & $<$ LOD -0.75 \\
\hline Methidathion & $99,(100)$ & 0.15 & 0.09 & 0.13 & $0.06-0.52$ \\
\hline$o, p^{\prime}-\mathrm{DDE}$ & $99,(100)$ & 1.23 & 0.83 & 1.02 & $0.27-4.73$ \\
\hline Tetrachlorvinphos & $99,(100)$ & 0.84 & 0.22 & 0.79 & $0.62-1.53$ \\
\hline Paclobutrazol & $99,(100)$ & 0.61 & 0.34 & 0.52 & $0.16-1.67$ \\
\hline Butachlor & $79,(80)$ & 0.3 & 0.17 & 0.3 & $<$ LOD-0.94 \\
\hline$\alpha$-Endosulfan & $99,(100)$ & 0.13 & 0.1 & 0.11 & $0.01-0.42$ \\
\hline Fenamiphos & $66,(67)$ & 0.49 & 0.33 & 0.43 & $<$ LOD-1.46 \\
\hline Napropamide & $0,(0)$ & $<\mathrm{LOD}$ & 0 & $<\mathrm{LOD}$ & $<\mathrm{LOD}$ \\
\hline Profenofos & $0,(0)$ & $<\mathrm{LOD}$ & 0 & $<\mathrm{LOD}$ & $<\mathrm{LOD}$ \\
\hline$p, p^{\prime}-\mathrm{DDE}$ & $99,(100)$ & 2.68 & 2.1 & 1.86 & $0.36-8.82$ \\
\hline Oxadiazon & $8,(8)$ & 0.01 & 0.03 & $<\mathrm{LOD}$ & $<$ LOD -0.17 \\
\hline Dieldrin & $74,(75)$ & 0.74 & 0.77 & 0.47 & $<$ LOD-2.71 \\
\hline$o, p^{\prime}-\mathrm{DDD}$ & $96,(97)$ & 0.32 & 0.18 & 0.29 & $<$ LOD -0.65 \\
\hline Oxyfluorfen & $99,(100)$ & 0.42 & 0.34 & 0.34 & $0.03-1.52$ \\
\hline Nitrofen & $99,(100)$ & 0.18 & 0.03 & 0.17 & $0.16-0.28$ \\
\hline Endrin & $56,(57)$ & 0.22 & 0.08 & 0.23 & $<$ LOD -0.36 \\
\hline
\end{tabular}




\begin{tabular}{llllll} 
Fluazifop-butyl & $79,(80)$ & 0.21 & 0.08 & 0.2 & $<$ LOD-0.37 \\
$\beta$-Endosulfan & $99,(100)$ & 0.64 & 0.32 & 0.62 & $0.1-1.74$ \\
Ethion & $96,(97)$ & 0.34 & 0.14 & 0.36 & $<$ LOD-0.66 \\
$p, p^{\prime}$-DDD & $99,(100)$ & 0.53 & 0.09 & 0.54 & $0.38-0.73$ \\
$o, p^{\prime}$-DDT & $99,(100)$ & 0.7 & 0.13 & 0.72 & $0.5-0.95$ \\
$p, p^{\prime}$-DDT & $99,(100)$ & 1.68 & 1.04 & 1.44 & $0.6-6.03$ \\
Pyridaphenthion & $99,(100)$ & 1.74 & 0.93 & 1.64 & $0.25-3.6$ \\
Bifenthrin & $66,(67)$ & 0.19 & 0.07 & 0.2 & $<$ LOD- 0.32 \\
Fenpropathrin & $96,(97)$ & 0.51 & 0.23 & 0.53 & $<$ LOD- 0.89 \\
Phosalone & $36,(36)$ & 0.11 & 0.03 & $<$ LOD & $<$ LOD- 0.19 \\
Delta-Cyhalothrin & $63,(64)$ & 0.19 & 0.08 & 0.21 & $<$ LOD- 0.33 \\
Permethrin & $79,(80)$ & 1.04 & 0.63 & 1.18 & $<$ LOD-2.17 \\
Coumaphos & $74,(75)$ & 1.24 & 0.76 & 1.34 & $<$ LOD-2.79 \\
Cyfluthrin & $66,(67)$ & 0.33 & 0.18 & 0.34 & $<$ LOD- 0.78 \\
Cypermethrin & $99,(100)$ & 0.14 & 0.05 & 0.12 & $0.07-0.23$ \\
Fenvalerate & $53,(54)$ & 0.78 & 0.62 & 0.89 & $<$ LOD-2.13 \\
Deltamethrin & $10,(10)$ & 0.28 & 0.27 & $<$ LOD & $<$ LOD-1.22 \\
\hline
\end{tabular}


Table S8. Comparison of mean concentrations of 7 SVOCs in this study with other studies $\left(\mu \mathrm{g} \mathrm{L}^{-1}\right)$.

\begin{tabular}{|c|c|c|c|c|c|c|c|c|c|c|c|}
\hline Country & Population & $\begin{array}{l}\text { Sample } \\
\text { size }\end{array}$ & $\begin{array}{l}\text { Yea } \\
\mathrm{r}\end{array}$ & $\begin{array}{l}\text { DnB } \\
\mathrm{P}\end{array}$ & DEHP & $\begin{array}{l}\text { PCB- } \\
153\end{array}$ & $\begin{array}{l}p, p^{\prime}- \\
\text { DDE }\end{array}$ & $\begin{array}{l}\beta- \\
\mathrm{HCH}\end{array}$ & $\begin{array}{l}\text { Hexachlorobenzen } \\
\text { e }\end{array}$ & $\begin{array}{l}\text { Total } \\
\text { PAH }\end{array}$ & Reference \\
\hline China & $\begin{array}{l}\text { general } \\
\text { population }\end{array}$ & 99 & $\begin{array}{l}201 \\
9\end{array}$ & 43.77 & 42.34 & 1.90 & 2.68 & 0.94 & 1.43 & 250.48 & $\begin{array}{l}\text { This } \\
\text { study }\end{array}$ \\
\hline Sweden & pregnant women & 42 & $\begin{array}{l}200 \\
8\end{array}$ & 2.8 & 17 & - & - & - & - & - & 8 \\
\hline China & $\begin{array}{l}\text { general } \\
\text { population }\end{array}$ & 153 & $\begin{array}{l}201 \\
3\end{array}$ & 4.19 & 11.13 & - & - & - & - & - & 9 \\
\hline $\begin{array}{l}\text { South } \\
\text { Korea }\end{array}$ & children & 59 & $\begin{array}{l}201 \\
3\end{array}$ & 54.96 & $\begin{array}{l}121.3 \\
1\end{array}$ & - & - & - & - & - & 10 \\
\hline China & pregnant women & 207 & $\begin{array}{l}201 \\
4\end{array}$ & 68.14 & $\begin{array}{l}187.1 \\
6\end{array}$ & - & - & - & - & - & 11 \\
\hline $\begin{array}{l}\text { South } \\
\text { Korea }\end{array}$ & children & 58 & $\begin{array}{l}201 \\
4\end{array}$ & 207.7 & 61.8 & - & - & - & - & - & 12 \\
\hline China & $\begin{array}{l}\text { general } \\
\text { population }\end{array}$ & 474 & $\begin{array}{l}201 \\
8\end{array}$ & 162.4 & 45 & - & - & - & - & - & 13 \\
\hline Germany & $\begin{array}{l}\text { general } \\
\text { population }\end{array}$ & 105 & $\begin{array}{l}201 \\
1\end{array}$ & - & - & 1.338 & 2.317 & - & 0.742 & - & 14 \\
\hline Spain & adults & 428 & $\begin{array}{l}201 \\
4\end{array}$ & - & - & 32.1 & 1.02 & 0.53 & - & - & 15 \\
\hline Slovakia & pregnant women & 973 & $\begin{array}{l}201 \\
5\end{array}$ & - & - & 2.1 & 6 & - & - & - & 16 \\
\hline Canada & pregnant women & 1258 & $\begin{array}{l}201 \\
5 \\
\end{array}$ & - & - & 0.04 & 0.3 & - & 0.24 & - & 17 \\
\hline
\end{tabular}




\begin{tabular}{|c|c|c|c|c|c|c|c|c|c|c|c|}
\hline France & pregnant women & 268 & $\begin{array}{l}201 \\
6\end{array}$ & - & - & 0.11 & 0.19 & 0.041 & 0.033 & - & 18 \\
\hline Belgium & pregnant women & 195 & $\begin{array}{l}201 \\
6\end{array}$ & - & - & 0.055 & 0.161 & & 0.019 & - & 19 \\
\hline China & pregnant women & 999 & $\begin{array}{l}201 \\
6\end{array}$ & - & - & - & 2.01 & 0.68 & - & - & 20 \\
\hline Belgium & pregnant women & 1105 & $\begin{array}{l}201 \\
7\end{array}$ & - & - & 0.06 & 0.22 & - & 0.999 & - & 21 \\
\hline Norway & pregnant women & 396 & $\begin{array}{l}201 \\
7\end{array}$ & - & - & 0.039 & 0.041 & - & 0.23 & - & 21 \\
\hline Slovakia & pregnant women & 449 & $\begin{array}{l}201 \\
7\end{array}$ & - & - & 0.311 & 1.03 & - & 0.399 & - & 21 \\
\hline Norway & $\begin{array}{l}\text { general } \\
\text { population }\end{array}$ & 53 & $\begin{array}{l}201 \\
7\end{array}$ & - & - & 1.25 & - & - & - & - & 22 \\
\hline Brazil & $\begin{array}{l}\text { general } \\
\text { population }\end{array}$ & 547 & $\begin{array}{l}201 \\
7\end{array}$ & - & - & - & 2.2 & 0.23 & - & - & 23 \\
\hline Spain & pregnant women & 1886 & $\begin{array}{l}201 \\
8\end{array}$ & - & - & 0.278 & 1.6 & - & - & - & 24 \\
\hline Canada & $\begin{array}{l}\text { general } \\
\text { population }\end{array}$ & 281 & $\begin{array}{l}201 \\
8\end{array}$ & - & - & 0.6 & 2 & - & - & - & 25 \\
\hline China & $\begin{array}{l}\text { general } \\
\text { population }\end{array}$ & 100 & $\begin{array}{l}201 \\
8\end{array}$ & - & - & - & 4.88 & 2.82 & 2.23 & - & 26 \\
\hline India & children & 50 & $\begin{array}{l}200 \\
8\end{array}$ & - & - & - & - & - & - & 125.55 & 27 \\
\hline America & pregnant women & 35 & $\begin{array}{l}201 \\
1\end{array}$ & - & - & - & - & - & - & 7.4 & 28 \\
\hline
\end{tabular}




\begin{tabular}{|c|c|c|c|c|c|c|c|c|c|c|c|}
\hline China & pregnant women & 103 & $\begin{array}{l}201 \\
2\end{array}$ & - & - & - & - & - & - & 79.36 & 29 \\
\hline Poland & pregnant women & 20 & $\begin{array}{l}201 \\
7\end{array}$ & - & - & - & - & - & - & 298.25 & 30 \\
\hline China & pregnant women & 14 & $\begin{array}{l}201 \\
8\end{array}$ & - & - & - & - & - & - & 4.67 & 31 \\
\hline China & pregnant women & 18 & $\begin{array}{l}201 \\
8\end{array}$ & - & - & - & - & - & - & 16 & 32 \\
\hline
\end{tabular}




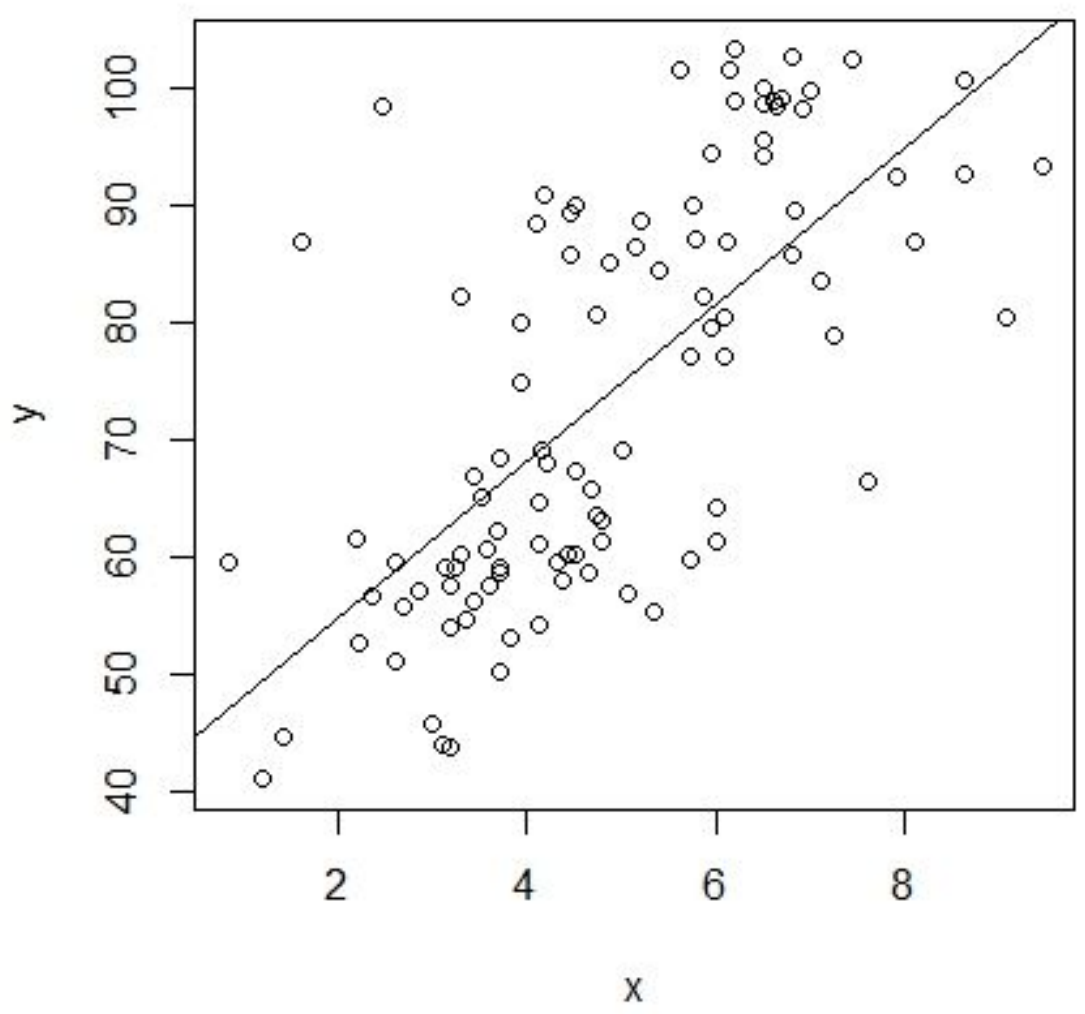

Figure S1. Pearson correlation of $\log$ Kow value and recovery rate $(\%)$ of target compounds. $\mathrm{x}=\operatorname{logKow}$ value, $\mathrm{y}=$ recovery $(\%), \mathrm{r}=0.68, \mathrm{p}$-value $=4.37 \mathrm{e}-15$. 

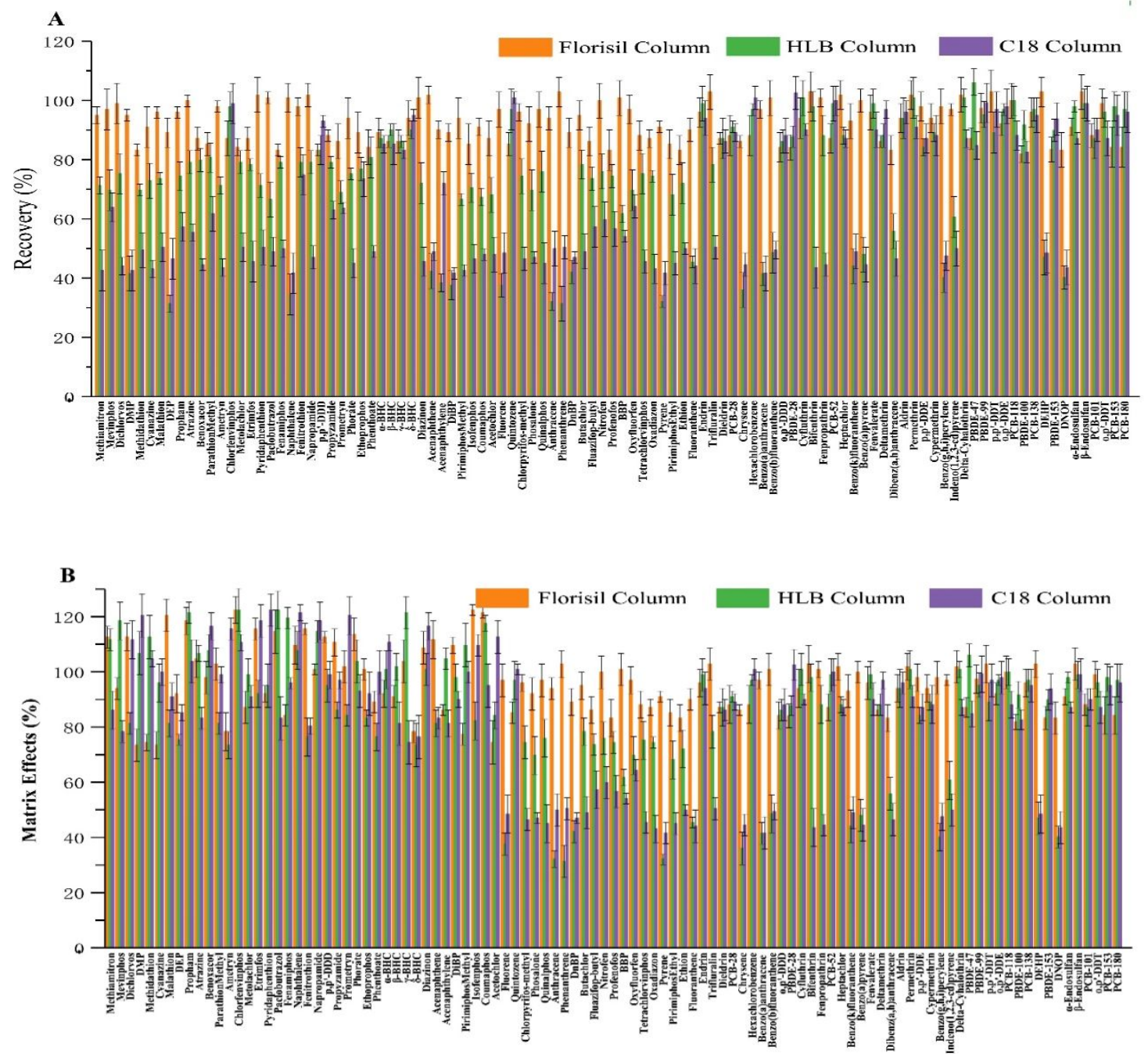

Figure S2. Recoveries (A) and matrix effects (B) of target analytes in serum samples and comparison with different SPE cartridges. Compounds are arranged from left to right according to LogKow value from small to large. 


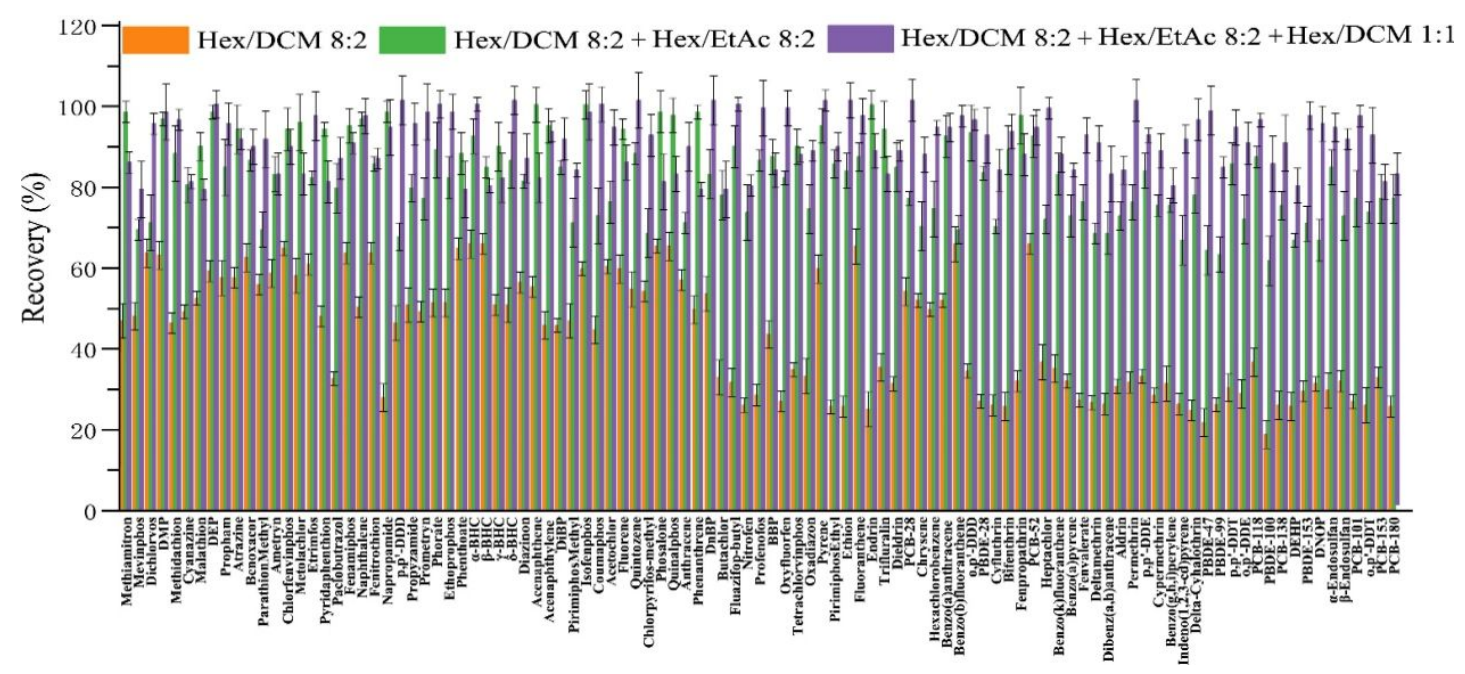

Figure S3. The influence of elution solvent mixtures on recovery efficiency $(n=3)$. The volume ratio of $2 \mathrm{~mL}$ of Hex/DCM (v/v, 8:2), $2 \mathrm{~mL}$ of Hex/EtAc (v/v, 8:2) and $2 \mathrm{~mL}$ of $\operatorname{Hex} / \mathrm{DCM}(\mathrm{v} / \mathrm{v}, 1: 1)$ were tested. 

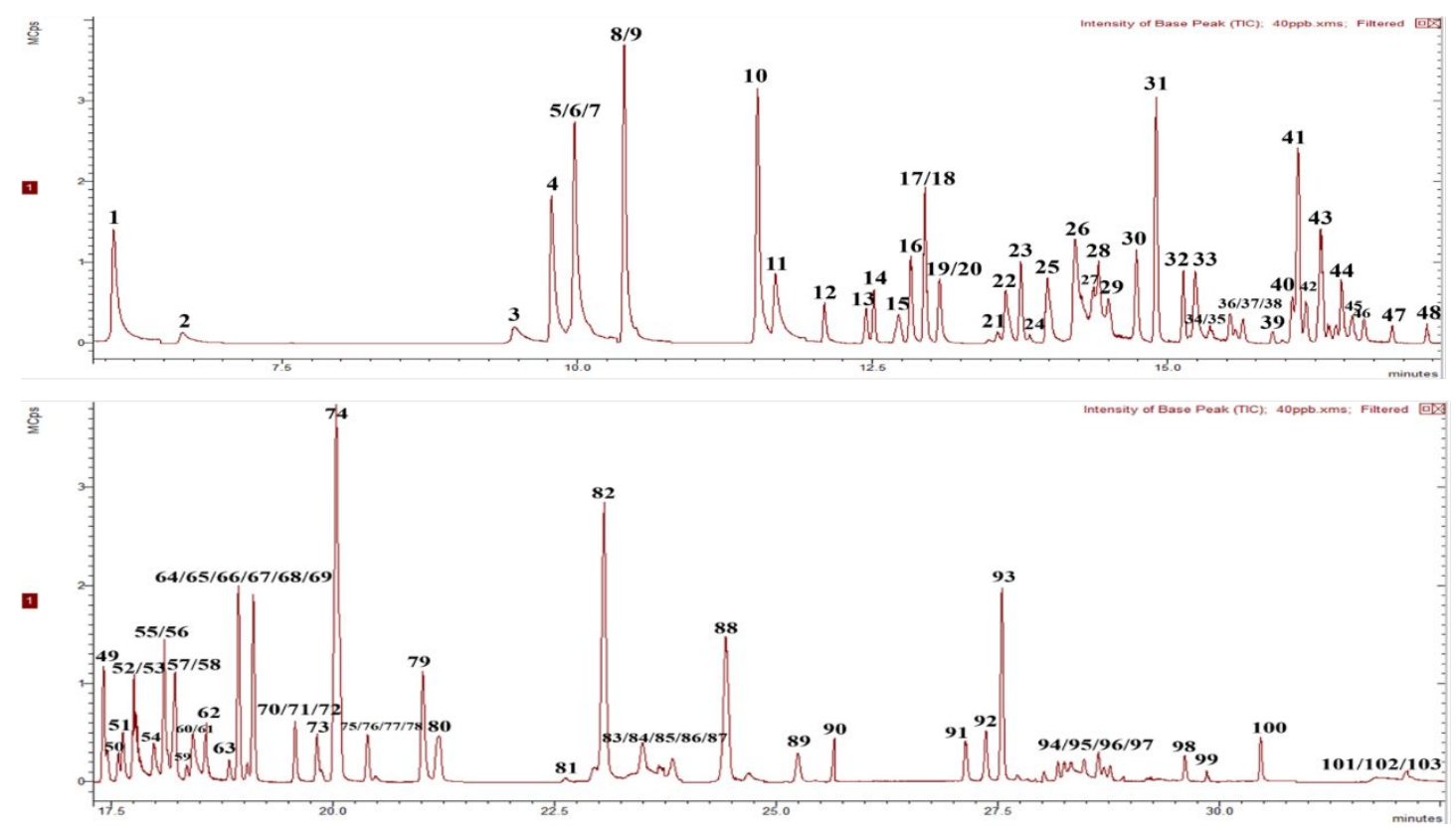

Figure S4. Reconstructed TIC chromatogram of 103 SVOCs (fetal bovine serum) spiked with the target compounds $\left(40 \mu \mathrm{g} \mathrm{L}^{-1}\right)$. 

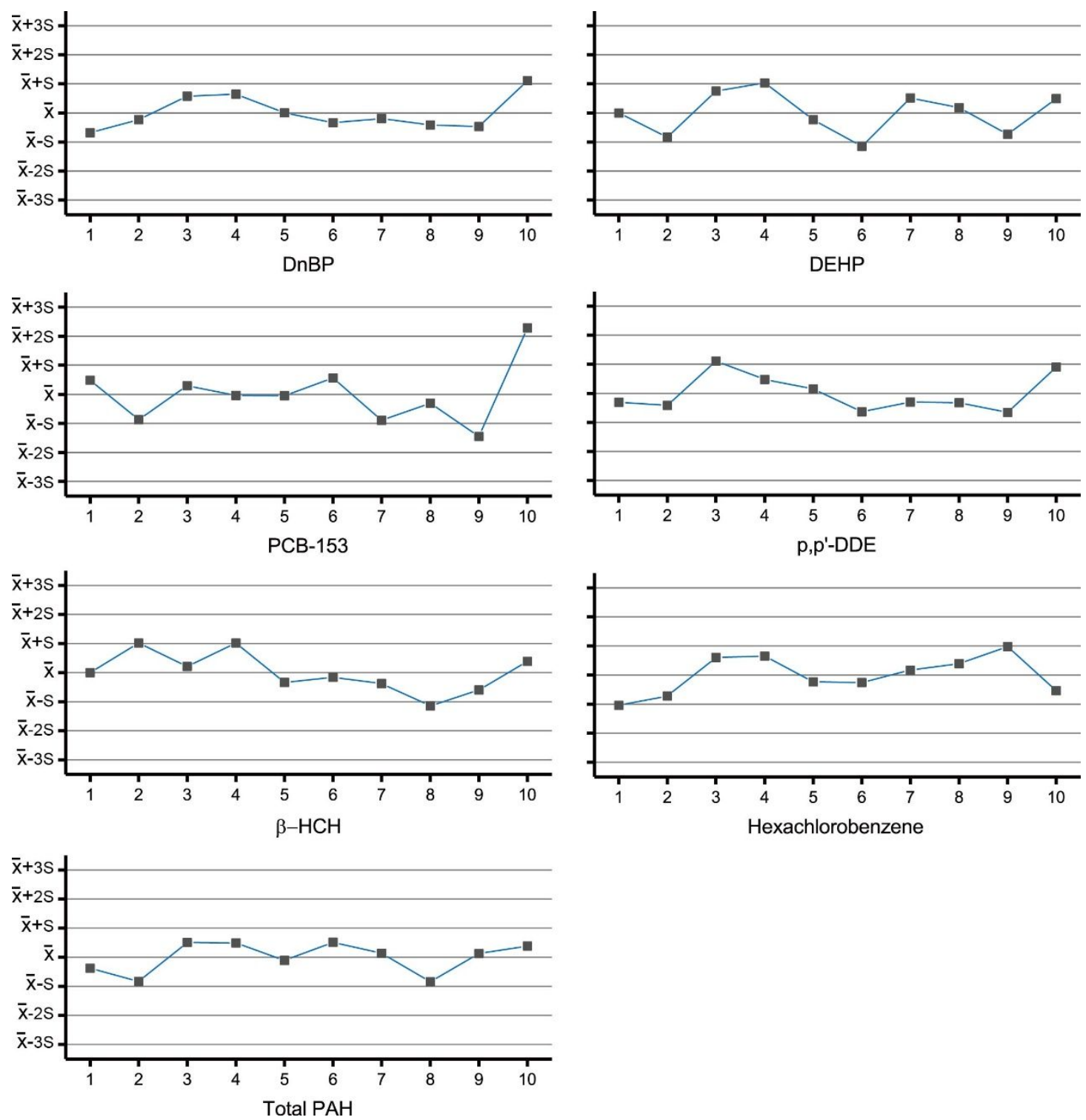

Figure S5. The analysis of QA/QC samples spiked with the target compounds in real sample testing $\left(10 \mu \mathrm{g} \mathrm{L}^{-1}\right)$. 


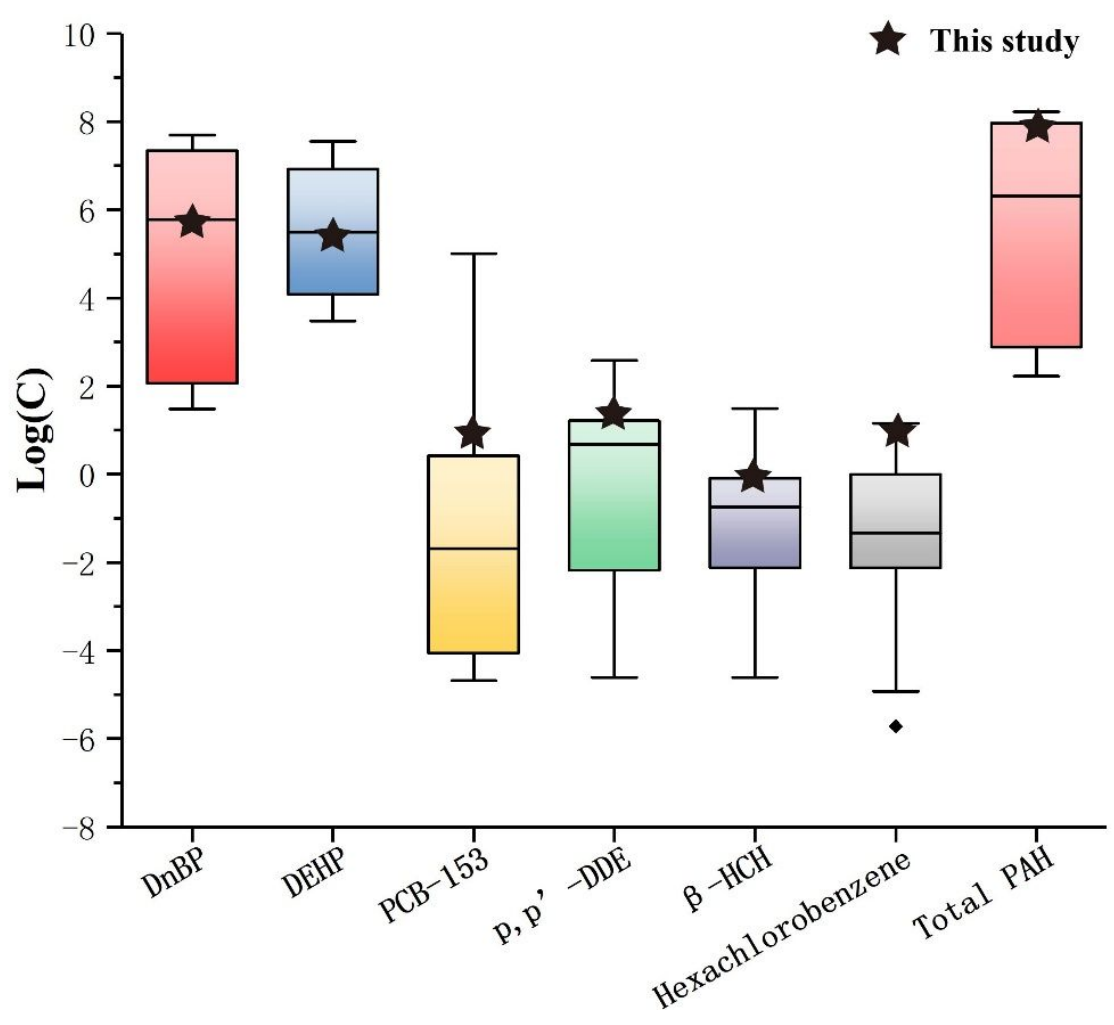

Figure S6. Comparison of Logarithmic conversion concentrations of 7 selected SVOCs in this study with other studies $\left(\mu \mathrm{g} \mathrm{L}^{-1}\right)$. 


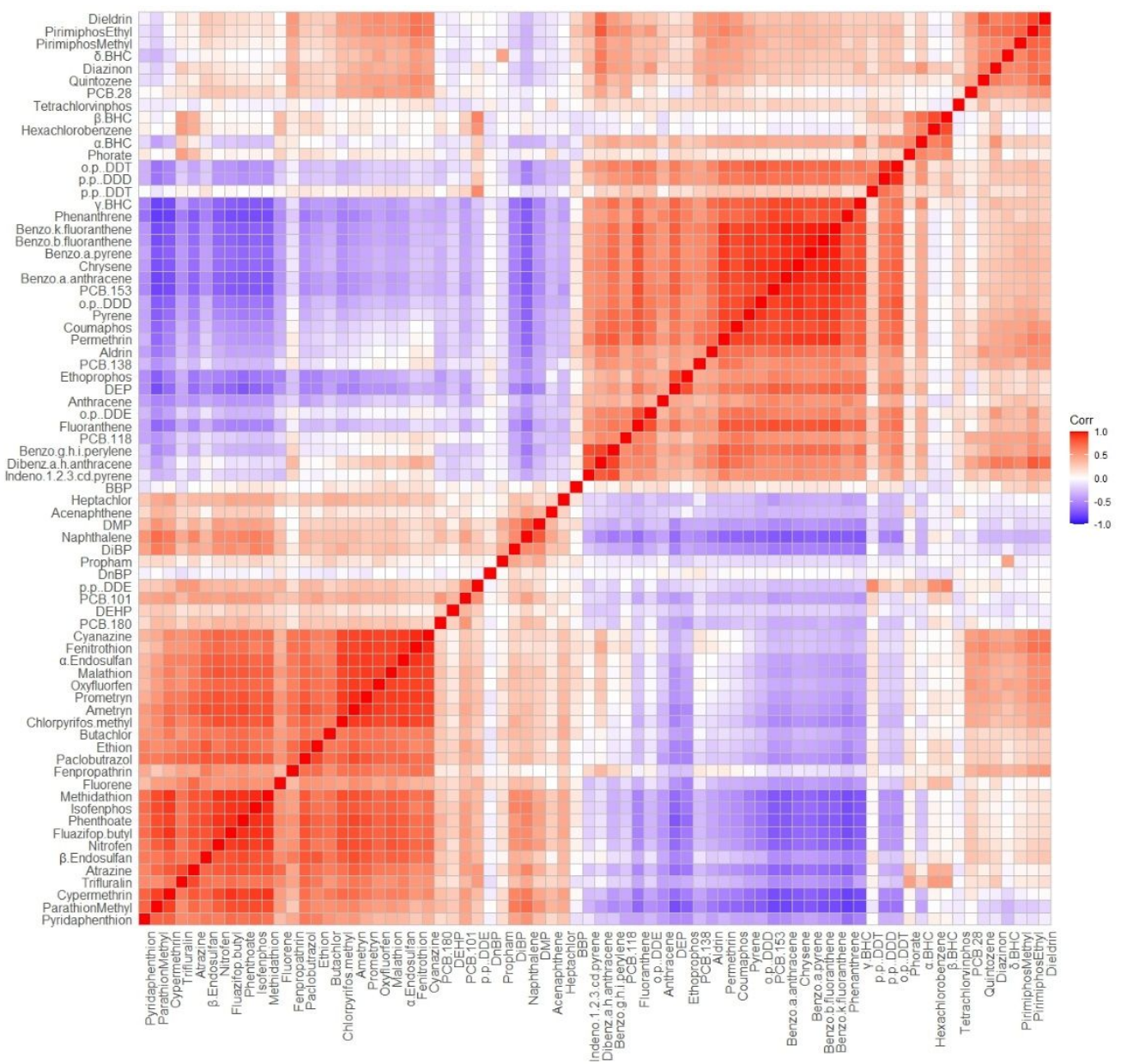

Figure S7. Heat map of pairwise correlations between chemical concentrations in serum. Red means positive correlation, white indicates no correlation, and blue represents negative correlation. 


\section{Reference}

1. Li, J.; Wang, P.; Shi, S.; Xue, J., Background biomonitoring of residue levels of 137 pesticides in the blood plasma of the general population in Beijing. Environ. Monit. Assess. 2018, 190, (5), 315.

2. Makino. M., Prediction of n-octanol/waterpartition coefficients of polychlorinated bisphenyls by use of computer calculated molecular properties. Chemosphere. 1998, 37, 13-26.

3. Caspersen, I. H.; Kvalem, H. E.; Haugen, M.; Brantsæter, A. L.; Meltzer, H. M.; Alexander, J.; Thomsen, C.; Frøshaug, M.; Bremnes, N. M. B.; Broadwell, S. L.; Granum, B.; Kogevinas, M.; Knutsen, H. K., Determinants of plasma PCB, brominated flame retardants, and organochlorine pesticides in pregnant women and 3 year old children in The Norwegian Mother and Child Cohort Study. Environ. Res. 2016, 146, 136-144.

4. Meng, G.; Feng, Y.; Nie, Z.; Wu, X.; Wei, H.; Wu, S.; Yin, Y.; Wang, Y., Internal exposure levels of typical POPs and their associations with childhood asthma in Shanghai, China. Environ. Res. 2016, 146, 125-135.

5. Michael, J. A.; Jeffrey, M. L.; John, W. S.; David, J. S.; Jennifer, N. L.; Susana, C.-A.; Santiago de la, P.; Patricia, M.; Sandra, Y., ASSESSMENT OF POLYCHLORINATED BIPHENYLS, ORGANOCHLORINE PESTICIDES, AND POLYBROMINATED DIPHENYL ETHERS IN THE BLOOD OF HUMBOLDT PENGUINS $(<\mathrm{i}>$ SPHENISCUS HUMBOLDTI $</ \mathrm{i}>)$ FROM THE PUNTA SAN JUAN MARINE PROTECTED AREA, PERU. J. Wildl. Dis. 2018, 54, (2), 304-314.

6. Lee, J. E.; Oh, H. B.; Im, H.; Han, S. B.; Kim, K. H., Multiresidue analysis of 85 persistent organic pollutants in small human serum samples by modified QuEChERS preparation with different ionization sources in mass spectrometry. J. Chromatogr. A 2020, 1623,461170 .

7. Jia, X.; Yin, S.; Xu, J.; Li, N.; Ren, M.; Qin, Y.; Zhou, J.; Wei, Y.; Guo, Y.; Gao, M.; Yu, Y.; Wang, B.; Li, Z., An efficient method to simultaneously analyze multiclass organic pollutants in human serum. Environ. Pollut. 2019, 251, 400-406. 
8. Wan, H. T.; Leung, P. Y.; Zhao, Y. G.; Wei, X.; Wong, M. H.; Wong, C. K. C., Blood plasma concentrations of endocrine disrupting chemicals in Hong Kong populations. Journal of Hazardous Materials 2013, 261, 763-769.

9. Högberg, J.; Hanberg, A.; Berglund, M.; Skerfving, S.; Remberger, M.; Calafat, A. M.; Filipsson, A. F.; Jansson, B.; Johansson, N.; Appelgren, M.; Håkansson, H., Phthalate Diesters and Their Metabolites in Human Breast Milk, Blood or Serum, and Urine as Biomarkers of Exposure in Vulnerable Populations. 2008, 116, (3), 334-339. 10. Jung, H.; Hong, Y.; Lee, D.; Pang, K.; Kim, Y., The association between some endocrine disruptors in human plasma and the occurrence of congenital hypothyroidism. Environmental Toxicology and Pharmacology 2013, 35, (2), 278-283.

11. Huang, Y.; Li, J.; Garcia, J. M.; Lin, H.; Wang, Y.; Yan, P.; Wang, L.; Tan, Y.; Luo, J.; Qiu, Z.; Chen, J.-a.; Shu, W., Phthalate Levels in Cord Blood Are Associated with Preterm Delivery and Fetal Growth Parameters in Chinese Women. PLOS ONE 2014, 9, (2), e87430.

12. Choi, J.; Eom, J.; Kim, J.; Lee, S.; Kim, Y., Association between some endocrinedisrupting chemicals and childhood obesity in biological samples of young girls: A cross-sectional study. Environmental Toxicology and Pharmacology 2014, 38, (1), 5157.

13. Zhang, S.-h.; Shen, Y.-X.; Li, L.; Fan, T.-t.; Wang, Y.; Wei, N., Phthalate exposure and high blood pressure in adults: a cross-sectional study in China. Environmental Science and Pollution Research 2018, 25, (16), 15934-15942.

14. Schettgen, T.; Gube, M.; Alt, A.; Fromme, H.; Kraus, T., Pilot study on the exposure of the German general population to non-dioxin-like and dioxin-like PCBs. International Journal of Hygiene and Environmental Health 2011, 214, (4), 319-325. 15. Henríquez-Hernández, L. A.; Luzardo, O. P.; Zumbado, M.; Camacho, M.; SerraMajem, L.; Álvarez-León, E. E.; Boada, L. D., Blood pressure in relation to contamination by polychlorobiphenyls and organochlorine pesticides: Results from a population-based study in the Canary Islands (Spain). Environmental Research 2014, $135,48-54$.

16. Jusko, T. A.; Roos, A. J. D.; Lee, S. Y.; Thevenet-Morrison, K.; Schwartz, S. M.; 
Verner, M.-A.; Murinova, L. P.; Drobná, B.; Kočan, A.; Fabišiková, A.; Čonka, K.; Trnovec, T.; Hertz-Picciotto, I.; Lawrence, B. P., A Birth Cohort Study of Maternal and Infant Serum PCB-153 and DDE Concentrations and Responses to Infant Tuberculosis Vaccination. 2016, 124, (6), 813-821.

17. Ashley-Martin, J.; Levy, A. R.; Arbuckle, T. E.; Platt, R. W.; Marshall, J. S.; Dodds, L., Maternal exposure to metals and persistent pollutants and cord blood immune system biomarkers. Environmental Health 2015, 14, (1), 52.

18. Debost-Legrand, A.; Warembourg, C.; Massart, C.; Chevrier, C.; Bonvallot, N.; Monfort, C.; Rouget, F.; Bonnet, F.; Cordier, S., Prenatal exposure to persistent organic pollutants and organophosphate pesticides, and markers of glucose metabolism at birth. Environmental Research 2016, 146, 207-217.

19. Remy, S.; Govarts, E.; Wens, B.; De Boever, P.; Den Hond, E.; Croes, K.; Sioen, I.; Baeyens, W.; van Larebeke, N.; Koppe, J.; Covaci, A.; Schettgen, T.; Nelen, V.; Legler, J.; Schoeters, G., Metabolic targets of endocrine disrupting chemicals assessed by cord blood transcriptome profiling. Reproductive Toxicology 2016, 65, 307-320.

20. Luo, D.; Pu, Y.; Tian, H.; Cheng, J.; Zhou, T.; Tao, Y.; Yuan, J.; Sun, X.; Mei, S., Concentrations of organochlorine pesticides in umbilical cord blood and related lifestyle and dietary intake factors among pregnant women of the Huaihe River Basin in China. Environment International 2016, 92-93, 276-283.

21. de Cock, M.; de Boer, M. R.; Govarts, E.; Iszatt, N.; Palkovicova, L.; Lamoree, M. H.; Schoeters, G.; Eggesbø, M.; Trnovec, T.; Legler, J.; van de Bor, M., Thyroidstimulating hormone levels in newborns and early life exposure to endocrine-disrupting chemicals: analysis of three European mother-child cohorts. Pediatric Research 2017, $82,(3), 429-437$.

22. Nøst, T. H.; Sandanger, T. M.; Nieboer, E.; Odland, J. Ø.; Breivik, K., The impacts of emission trends of POPs on human concentration dynamics: Lessons learned from a longitudinal study in Norway (1979-2007). International Journal of Hygiene and Environmental Health 2017, 220, (4), 776-781.

23. do Nascimento, F. P.; Kuno, R.; Lemes, V. R. R.; Kussumi, T. A.; Nakano, V. E.; Rocha, S. B.; de Oliveira, M. C. C.; de Albuquerque Kimura, I.; Gouveia, N., 
Organochlorine pesticides levels and associated factors in a group of blood donors in São Paulo, Brazil. Environ. Monit. Assess. 2017, 189, (8), 380.

24. Ballester, F.; Iñiguez, C.; Murcia, M.; Guxens, M.; Basterretxea, M.; Rebagliato, M.; Vioque, J.; Lertxundi, A.; Fernandez-Somoano, A.; Tardon, A.; Sunyer, J.; Llop, S., Prenatal exposure to mercury and longitudinally assessed fetal growth: Relation and effect modifiers. Environmental Research 2018, 160, 97-106.

25. Parajuli, R. P.; Goodrich, J. M.; Chan, L. H. M.; Ayotte, P.; Lemire, M.; Hegele, R. A.; Basu, N., Genetic polymorphisms are associated with exposure biomarkers for metals and persistent organic pollutants among Inuit from the Inuvialuit Settlement Region, Canada. Sci. Total Environ. 2018, 634, 569-578.

26. Li, J. X.; Wang, P. S.; Shi, S. M.; Xue, J., Background biomonitoring of residue levels of 137 pesticides in the blood plasma of the general population in Beijing. Environ. Monit. Assess. 2018, 190, (5), 15.

27. Singh, V. K.; Patel, D. K.; Jyoti; Ram, S.; Mathur, N.; Siddiqui, M. K. J., Blood levels of polycyclic aromatic hydrocarbons in children and their association with oxidative stress indices: An Indian perspective. Clinical Biochemistry 2008, 41, (3), $152-161$

28. Sexton, K.; Salinas, J. J.; McDonald, T. J.; Gowen, R. M. Z.; Miller, R. P.; McCormick, J. B.; Fisher-Hoch, S. P., Polycyclic Aromatic Hydrocarbons in Maternal and Umbilical Cord Blood from Pregnant Hispanic Women Living in Brownsville, Texas. 2011, 8, (8), 3365-3379.

29. Guo, Y.; Huo, X.; Wu, K.; Liu, J.; Zhang, Y.; Xu, X., Carcinogenic polycyclic aromatic hydrocarbons in umbilical cord blood of human neonates from Guiyu, China. Sci. Total Environ. 2012, 427-428, 35-40.

30. Zajda, K.; Ptak, A.; Rak, A.; Fiedor, E.; Grochowalski, A.; Milewicz, T.; Gregoraszczuk, E. L., Effects of human blood levels of two PAH mixtures on the AHR signalling activation pathway and CYP1A1 and COMT target genes in granulosa nontumor and granulosa tumor cell lines. Toxicology 2017, 389, 1-12.

31. Zhang, Y.; Zhao, Y.-G.; Chen, W.-S.; Cheng, H.-L.; Zeng, X.-Q.; Zhu, Y., Threedimensional ionic liquid-ferrite functionalized graphene oxide nanocomposite for 
pipette-tip solid phase extraction of 16 polycyclic aromatic hydrocarbons in human blood sample. Journal of Chromatography A 2018, 1552, 1-9.

32. Dong, X.; Wang, Q.; Peng, J.; Wu, M.; Pan, B.; Xing, B., Transfer of polycyclic aromatic hydrocarbons from mother to fetus in relation to pregnancy complications. Sci. Total Environ. 2018, 636, 61-68. 